\title{
The significance of employee behaviours and soft management practices to avoid digital waste during a digital transformation
}

\author{
Jamila Alieva
}

Faculty of Engineering and the Environment, University of Gävle, Gavle, Sweden, and

Daryl John Powell

Department of Industrial Ecosystems, SINTEF Manufacturing AS, Raufoss, Norway and Department of Industrial Economics and Technology Management, Norwegian University of Science and Technology, Trondheim, Norway

\begin{abstract}
Purpose - The purpose of this study is to investigate the perceived effects between soft management practices, employee behaviours and the implementation of digital technologies in manufacturing plants, as well as how these relate to the emergence of digital waste.

Design/methodology/approach - This paper uses case-based research. Data was collected in two large manufacturing companies based in Norway and Sweden through semi-structured interviews with two management representatives and four shop-floor employees. The data was used to evaluate 29 variables describing lean- and total quality management (TQM)-associated employee behaviours and soft management practices, in light of digital transformation.

Findings - The results suggest that several variables were positively influenced by the digital transformation process. These were top management leadership, middle management involvement, employee education, corporate social responsibility focus, innovation, knowledge sharing, work-family balance, psychological capital, job satisfaction and career commitment. Training employees, creativity, discretionary effort, turnover intention and proactivity appear to be negatively influenced by digital transformation The findings also indicate that several soft management practices and employee behaviours were not only influenced by manufacturing digitalization but also themselves influenced the process. The potential for digital waste creation was also detected in several variables, including reward and recognition and training employees.
\end{abstract}

Practical implications - Managers, practitioners and academics may learn about the importance of certain managerial practices and employees' behavioural needs during the digital transformation process. The findings may help in prioritizing TQM and soft lean management practices and certain employee behaviours during the digital transformation and in creating awareness of digital waste.

Originality/value - This study builds on several existing studies discussing the impact of digital transformation on soft management practices and employee behaviours. It provides insights from a lean and

(C) Jamila Alieva and Daryl John Powell. Published by Emerald Publishing Limited. This article is published under the Creative Commons Attribution (CC BY 4.0) licence. Anyone may reproduce, distribute, translate and create derivative works of this article (for both commercial and noncommercial purposes), subject to full attribution to the original publication and authors. The full terms of this licence maybe seen at http://creativecommons.org/licences/by/4.0/legalcode

The authors would like to acknowledge support from the Research Council of Norway for the project Lean Digital and the Center for Logistics and Innovative Production research group at the University of Gävle for the project Lean and Digitalization.

Received 27 July 2021 Revised 14 October 2021 3 February 2022 Accepted 4 February 2022 
IJLSS

14,1

TQM angle and offers a means of prioritizing certain practices and behaviours during a digital transformation. This study also highlights the significance of digital waste.

Keywords Non-utilized talent, Digital transformation, Lean management, TQM, Digitalization, Employee behavior, Digital waste

Paper type Research paper

\section{Introduction}

The role of employees in manufacturing plants in times of digital transformation and intensive technology adoption poses new challenges to management in establishing valueoriented processes in the most efficient yet digital way (Parschau and Hauge, 2020; Popkova and Sergi, 2020). A number of studies discuss the risk of employees' replacement by advanced technologies (Adam et al., 2019; Parschau and Hauge, 2020; Popkova and Sergi, 2020; Soukupova et al., 2020). The uncertainty related to future work tasks and the need for clarification of what a future workplace in digitalized environments stands for has led some young employees of smart factories to become anxious and afraid (Adam et al., 2019). In a questionnaire survey of large manufacturing enterprises, $64 \%$ out of 435 respondents perceived Industry 4.0 as a potential threat to their job position (Soukupova et al., 2020).

There is, however, hope. For example, Popkova and Sergi (2020) forecast that by the year 2030, social entrepreneurship will use the opportunities of Industry 4.0 for optimization of its activities but will reject full automatization, using human intellect and artificial intelligence simultaneously. Several studies also focus on the successful collaboration of manufacturing employees and digital technologies, as well as increased qualifications of new - digital era shop-floor employees (Ammar et al., 2021; Chaka, 2020; Kipper et al., 2021; Maisiri and Van Dyk, 2021; Tortorella et al., 2021; Vereycken et al., 2021). According to Ammar et al. (2021), digital technologies help companies optimize their material and inventory, leading to cost reductions. However, a concerning discussion around the emergence of digital waste is beginning to emerge (Alieva and Haartman, 2020; Powell et al., 2018). For example, digital waste can be an outcome of inefficient usage of technologies by manufacturing employees.

With remote technologies, on-site and off-site employees can easily collaborate and ultimately reduce communication gaps, as well as maintain smart predictive analysis. Manufacturing employees with high levels of technological intensity and technology adoption can progress in human-centred continuous improvement and achieve higher operational performance (Tortorella et al., 2021). This new type of manufacturing employee is expected to combine socio-cultural skills, business vision and knowledge about data analysis and digital technologies (Agostinho and Baldo, 2021). There is also a need for a new approach to train manufacturing employees through the integrated efforts between government, universities and manufacturing companies (Kipper et al., 2021). The role of management in the evaluation of risks, opportunities and critical success factors (CSFs) has been associated with the implementation of Industry 4.0 projects (Moeuf et al., 2020). Employees' soft factors and their behaviours play a big role in adapting to changes in organization (Gaiardelli et al., 2019; Georgiev and Ohtaki, 2019; Van and Nafukho, 2019). The concentration power and involvement of managers can mobilize employees for digital transformation or slow down that transformation (Moeuf et al., 2020). Suitable management practices can therefore play a vital role in rethinking and redesigning digitalized organizations by facilitating learning, enhancing capability and innovation (Shamim et al., 2016).

In the lean philosophy, people represent a core part of the value creation, waste reduction and continuous improvement activities. Such processes are highly dependent on employees' commitment and engagement in problem-solving and learning (Liker, 2004; Slack et al., 
2010; Womack et al., 1990). Poor leadership, resistance to change and a lack of motivation can lead to the failure of lean implementation (Ahuja et al., 2019; Morton et al., 2019; Toledo et al., 2019; Zainuddin et al., 2019). Industry 4.0 is also pushing the digital transformation of lean organizations, where employees remain critical for business success (Benešová and Jiří Tupa, 2017; Rauch et al., 2020; Richert et al., 2016; Stöhr et al., 2018).

Yet research is lacking that discloses if employees are supporters of or barriers to digital transformation, with the possible risks associated with job qualifications, new skills acquisition or the fear of being replaced by digital technologies (Gaiardelli et al., 2019; Georgiev and Ohtaki, 2019). Georgiev and Ohtaki (2019) discuss soft factors for successful total quality management (TQM) implementation, in which most factors overlap with the soft lean management practices discussed by Gaiardelli et al. (2019). Van and Nafukho (2019) also discuss employee behaviours - performance, proactivity, job satisfaction - which are likely to be impacted under the soft factors discussed by Georgiev and Ohtaki (2019) and Gaiardelli et al. (2019). The consideration of soft factors under the influence of digital technologies has been investigated in the management level (Antonizzi and Smuts, 2020; Mugge et al., 2020; Purba, 2021), customer and supplier level (Buer et al., 2021; Grandinetti et al., 2020; Rossini et al., 2021), employee level (Albukhitan, 2020; Mokudai et al., 2021; Raweewan and Kojima, 2020) and quality and environmental level (Llopis-Albert et al., 2021; Mugge et al., 2020; Raweewan and Kojima, 2020). The impact of digital transformation on employee behaviours has also been discussed on intrarole behaviours level (Chan et al., 2021; Dutta et al., 2020; Martínez-Caro et al., 2020), extra-role behaviours level (Haipeter, 2020; Jones et al., 2021; Kim and Park, 2021) and at the personal development and growth level (Choi et al., 2020; Lei et al., 2020; Wang and Han, 2020).

In this study, we build on the previous research by investigating soft (TQM and lean) management practices and specific employee behaviours in terms of their relevance and impact in digital transformation, where we also add the dimension of digital waste to this exciting field of research. The study adds to the current knowledge and studies of soft factors (lean and TQM) and allows us to review these variables in a physical setting, as well as to prioritize the focus of importance among them - making recommendations to organizations engaging in digital transformation to avoid digital waste.

\subsection{Research objective}

The objective of this research is to investigate soft management practices when new digital technologies are at the initial stage of implementation in lean manufacturing (LM) companies. The study also evaluates employee behaviours as a construct of the implementation of digital technologies in manufacturing plants, as well as how this relates to the emergence of digital waste.

\section{Towards a conceptual model}

In this section, we propose a conceptual model to guide the investigation, which is based on extant literature of digitalization of manufacturing, soft management practices (lean and TQM) and employee behaviours. Based on the literature reviewed, we propose two research questions derived from the literature.

\subsection{Digitalization of manufacturing}

Digitalization is a phenomenon that has been popularized with the onset of Industry 4.0. To understand what digitalization entails, one must distinguish between digitization and digitalization (Bloomberg, 2018). Digitization simply refers to taking analogue information and encoding it in a digital format so that computers can store, process and transmit such information (Bloomberg, 2018; Legner et al., 2017). Digitalization, on the other hand, is the 
IJLSS

14,1

process of using digital technologies and information to transform business operations - a so-called digital transformation (Legner et al., 2017; Reis et al., 2020).

Liker (2004) defines waste as an activity or process that takes time but does not add value for customers. Womack et al. (1990) discuss waste elimination as the process of mapping all the activities and keeping only those that add value while eliminating those that do not add any. According to Leksic et al. (2020), lean adoption should be supported by 5S, kaizen, kanban, poka-yoke and total preventive maintenance (TPM), because these waste management techniques reduce several types of waste. It will help to achieve a quicker and higher level of lean maturity. Sodhi et al. (2020) discuss the lean method in the context of waste reduction as a spotlighting in investigating work processes to decrease process duration and dispense with waste. There is strong connectivity between lean tools and manufacturing waste reduction in industrial processes (Purushothaman et al., 2020). Logesh and Balaji (2020) raise the topic of the green environment, which can be affected by the reduction of lean waste. Ejsmont and Gladysz (2020) propose a framework for waste typology combined with the Industry 4.0 potential to decrease wastes. Possibilities of using Industry 4.0 solutions in the support of lean techniques depend on the degree of their complexity and the opportunity of using them in manufacturing plants (Ejsmont and Gladysz, 2020). The greatest possibilities for their application are in kanban, pull signals, just in time (JIT) and just in sequence. There are lean techniques that can use only a few Industry 4.0 tools, such as 5S, cellular manufacturing and continuous flow (Ejsmont and Gladysz, 2020).

Alieva and Haartman (2020) focus on the topic of waste under the influence of digital technologies, offering a definition of digital waste as uncollected, unprocessed or misinterpreted product and production data. Romero et al. (2019d) discuss the issue of buffer waste in the cyber-physical production system. While digital waste currently appears to be less of a problem, there is a challenge with the storage and retrieval of large amounts of unnecessary data (Romero et al., 2019d). Muda is any data that does not contribute to making an informed decision, whereas buffer waste is created by mura or muri and can consequently not be reduced or eliminated without creating more waste (Romero et al., 2019d). Industrial examples for buffer waste are physical to physical, physical to digital, digital to physical and digital to digital (Romero et al., 2019d). Powell et al. (2018) focus on new technologies for detecting and eliminating potential physical waste in production processes, preventing it through virtual models and simulation systems based on advanced data analytics. Powell et al. (2018) also focus on identifying and eliminating digital waste that may come into existence in the cyber world due to the non-use (lost digital opportunities) or over-use (abused digital capabilities) of new digital/smart manufacturing technologies. In this study, we follow the definition of digital waste proposed by Powell et al. (2018), where digital waste is any non-value-adding digital activity to personnel, materials, machines, methods or measurements in LM companies influenced by digital technologies.

Digital transformation is the adoption of digital technology to transform services or businesses, through replacing analogue or manual processes with digital processes or replacing older digital technology with newer (O'Donnell, 2017).

There are five pillars for digital transformation integrating lean: digital strategic management, processes re-engineering management, digital technology management, change people management and digital risk management (Romero et al., 2019a). Digital strategy development is an important part of transformation, where personnel commitment starts bottom up and top managers involve their knowledge in the top-down phase of digitalization (Demeter et al., 2021). According to Schumacher et al. (2020), a lean production system is challenged by digital transformation on the level of methods and tools. There are 
several indicators for digitally driven change within lean production system - strategy adapted to Industry 4.0 characteristics, lean principles compatible to Industry 4.0 technologies, lean methods induced by digital transformation, lean production framework and productivity converging towards saturation, shop-floor elements and their digital integration. According to Romero et al. (2019b), automation with a human touch (jidoka) is the main principle for small- and medium-sized enterprises digital transformation. Jidoka combines both automation approach and learning systems, which allow improving the efficiency of the manufacturing process and adopting automation. According to Demeter et al. (2021), there are four stages of digital manufacturing transformation through the lenses of the dynamic capability components of adaptation: sensing capability, absorptive capacity, integrative capability and relational capability.

Digital adoption is also an important part of digital transformation. It is a change and learning mechanism that allows individuals to understand the potential of digital resources, accept and use such resources to achieve their goals and leverage each technology to the fullest to drive innovation and optimize processes (Mura, 2020). Romero et al. (2019b) propose the gradual introduction of full automation operations of formerly manual functions. It would allow the employees to lead the change towards semi-automated and fully automated processes based on their manufacturing process knowledge and boost their productivity in an affordable way. Ghobakhloo and Ching (2019) discuss the integration of modern smart manufacturing with information and digital technologies (SMIDT), where technological, organizational and environmental factors define the decision for SMIDT adoption. Machine and process controllers, industrial actuators and sensors, and enterprise resource planning were the most frequently implemented SMIDT. According to Romero et al. (2019c), the adoption of manufacturing technologies contributes to predictable and stable processes outputs. The adoption of digital poka-yoke (mistake proofing) allows recording the actions taken by each operator, producing real-time tutorials, speeding up operations and minimizing errors and the need to redo work. Also, Romero et al. (2020) discuss the importance of gemba walks (shop-floor observation) as an important means of vertical integration in LM. Traditional gemba is limited to one location only, whereas adoption of digital technologies expands gemba's opportunities, allowing gemba to be augmented, advanced virtual, automated guided and human cyber-physical.

\subsection{Soft management practices (lean and total quality management)}

Saxena and Rao (2019) discuss similarities and variations between TQM, Six Sigma and lean and found that the concepts are complementary and should be used to strengthen the values of TQM within an organization. According to Henao et al. (2019), both JIT and TQM adoption require the social system to develop the skills and desired level of worker involvement to avoid harmful consequences in operational and safety performance. The combination of lean practice, JIT and TQM leads to operational performance improvement through the support of goal-oriented practices and increased capability in dealing with variations affecting the quality, delivery, flexibility or cost. Romero et al. (2019a) discuss TQM and quality circles in digital LM through the framework where quality standards vary based on their objectives and tasks, dependent on human and digital capabilities. Respect for people should remain a powerful lean attribute in the age of new technologies, with automation combined with human creativity, ingenuity and innovation in a strategic way for quality planning, quality control, quality assurance and quality improvement. Zainuddin et al. (2019) discuss the combination of TQM and LM of green management systems (GMS) for the Quality Green Lean Energy Leadership Management System. The model involves leadership/management practices with integrated TQM, LM and GMS. These practices 
IJLSS

14,1

6

support leadership requirements for the effective management system. According to Bai et al. (2019), the lists of bundles of LM practices include JIT, TQM, TPM, human resource management, controlled processes, productive maintenance and involved employees. Iqbal et al. (2020) draw conclusions about strategic capabilities that can help firms to meet diverse sets of market demands, by comparing agile and LM, where JIT and TQM were considered as critical elements of the LM paradigm. According to García-Alcaraz et al. (2019a), TQM is a LM tool that focuses on securing the production of goods that fulfil design specifications and target customer satisfaction, where the human factor plays a key role in the success of TQM through the managerial commitment, employee integration, training and education processes. There is a strong link between lean and TQM soft management practices, with many of those variables overlapping (Table 1$)$.

Agus and Selvaraj (2020) examined the importance of incorporating both technicaloriented and people-oriented TQM, where benchmarking, quality measurement and process improvement significantly impacted production performance and productivity. Meanwhile, people-oriented dimensions such as employee focus, customer focus and supplier relations had an impact on enhancing productivity. Yan et al. (2019) proposed the framework for soft CSFs of TQM to optimise the quality management system of manufacturing companies. The quality-oriented organizational climate and innovation of supplier management concept and methods lead to better-quality performance and business results. Another important aspect is a top management commitment and the combination of quality planning with company strategy to be deployed at each level of the organization. According to Talapatra et al. (2019), human resources, strategy and structure are the significant enabling factors in TQM implementation. Georgiev and Ohtaki (2019) discussed the importance of soft TQM as part of the TQM implementation process, where 12 CSFs were defined and evaluated. In comparison, top management involvement and leadership are the soft factors widely discussed in the literature, while middle management involvement and support, reward and recognition, and corporate social responsibility focus have not been considered enough to yield explicit knowledge about their influence on the TQM implementation process. According to Halim et al. (2019), successful TQM implementation depends on culture and people, systems and techniques development, measurement and feedback. Top management and decision-makers are expected to prioritise culture and people factors, which include employee involvement, before implementing TQM. García-Alcaraz et al. (2019b) discuss factors involved in the success of TQM programs linked to the operational benefits of a

\begin{tabular}{|c|c|c|}
\hline & Georgiev and Ohtaki (2019) & Gaiardelli et al. (2019) \\
\hline \multirow{6}{*}{ Overlapping soft factors } & Success (soft) factors for the TQM & Soft lean management practices \\
\hline & Top management involvement and leadership & Top management leadership \\
\hline & Teamwork & Small group problem solving \\
\hline & Training and education & Training employees \\
\hline & Customer focus & Customer involvement \\
\hline & Supplier management (involvement) & Supplier partnership \\
\hline \multirow[t]{7}{*}{ Other soft factors } & (Quality) policy and strategy & Continuous improvement \\
\hline & Middle management involvement and support & \\
\hline & Employee involvement and empowerment & \\
\hline & Staff evaluation & \\
\hline & Reward and recognition & \\
\hline & Communication management & \\
\hline & Corporate social responsibility focus & \\
\hline
\end{tabular}

Table 1.

Soft management practices (TQM and lean)
Communication management

Corporate social responsibility focus 
manufacturing system, through the structural equation model that integrates three latent variables related to internal human resources: managerial commitment, employee integration, and training and education. Durairatnam et al. (2019) discuss the failure of TQM implementation to improve performance, finding a lack of attention to reviews of peoplerelated TQM practices, organizational culture, organizational justice and employee work attitudes. According to Durairatnam et al. (2019), employee work-related attitudes are mediators in the relationship between people-related TQM practices and quality performance. Bugdol (2020) discusses failure in TQM implementation and maintenance through the incorrect allocation of resources and poorly structured involvement of social processes. The lack of mental empowerment and the domination of the structural empowerment leads to contradictory expectations, in particular with employees, as well as excessive emphasis on employee commitment.

\subsection{Employee behaviours}

According to Womack et al. (1990), respect for people is a core element of the lean enterprise. Coetzee et al. (2019) discuss the lack of framework explaining the "respect for people" lean principle. They define a difference between product value streams that focus attention on problems and people value streams that bring people able to solve these problems (Coetzee et al., 2019). Nagaraj et al. (2019) propose a model with human factors incorporated in the value stream map to evaluate them with lean parameters. Results of that study suggest that greater attention to the human factor of lean implementation leads to the improvement of workers' life quality and operational performance. Gaiardelli et al. (2019) propose a model for lean implementation, taking into account the role of human factors in achieving superior operational performance. Operational outcome is highly dependent on hard and soft lean practices, physical work environment and job characteristics. The employee behaviour outcome in combination with physical work and job characteristics influences the operational performance. Gaiardelli et al. (2019) discovered to what extent human factors are affected by the implementation of hard and soft lean practices to achieve long-term performance. They found a short-term direct relationship between the implementation of lean practices and physical work environment and job characteristics, directly connected to operational outcome. In the long term, operational performance is influenced by employee behaviour outcome and depends on physical work environment as well as job characteristics. Sancha et al. (2019) discuss the role of temporary work on the LMoperational performance relationship, looking at cost, quality, delivery and flexibility. The use of temporary work has a positive impact on LM and flexibility performance. GarcíaAlcaraz et al. (2019b) discussed the importance of human resources integration in JIT lean technique implementation within the production process. As a result, the managers establish the relationships with suppliers and integrate human resources. Martens (2020) examined leadership styles in combination with two lean principles, respect for people and continuous improvement, with a conclusion that management-driven organizations seem to be soft factors of human behaviour driven by leadership. Toledo et al. (2019) propose that leadership promote activities to maintain lean management within the organization: selfdevelopment, coaching and development of employees, kaizen support, and goals and vision creation. Vukadinovic et al. (2019) propose a model which meets demands of lean philosophy, concepts of safety and employee efficiency, which leads to the gap reduction between expected and real performances of human resources of entry-level employees and enables the effective and efficient transition from academic to industrial environment. According to Minh et al. (2019), customer relationship, human resources and product design practices had positive effects on job satisfaction. However, process and equipment practices 
IJLSS

14,1

had a negative effect on job satisfaction. Ahuja et al. (2019) discuss the influence of CSFs in the adoption of sustainable manufacturing, where there are a number of parameters playing a highly significant role in the efficient adoption process: green motivation, customer relationship management, management leadership, communication and strategic alignment.

Zhou and Velamuri (2018) assert that the success factors for employee innovative behaviour are the key enablers for competitiveness. Zhou and Velamuri (2018) revealed that reward and pay, cross-functional cooperation and company innovation strategy are the key factors to foster employee innovative behaviour, and they found enhancing cross-functional cooperation and common goals among different units to be the tactic to implement those factors successfully within the manufacturing organization. Pham et al. (2016) discovered the relationships between organizational learning, top management support, innovative behaviour, employee commitment and organizational performance, and found strong links between innovative behaviour and organizational performance in the workplace. Hee and Jing (2018) examined the relationships among compensation and benefits, work-life policies, performance appraisal and training and development and employee performance, finding training and development to be the most important factor that positively influences employee performance, followed by performance appraisal. Santhanam and Srinivas (2019) examined the impact of engagement on job burnout and turnover intention among bluecollar workers in manufacturing facilities, where disengaged employees are in the risk group. Happiness is a significant moderating factor impacting employee engagement, burnout and turnover intention. According to Santhanam and Srinivas (2019), TQM and human resource management should be arranged with a focus on engagement, emotional protection and psychological safety of shop-floor workers to achieve international standards on quality management. Morton et al. (2019) discuss the importance of employee engagement in organizational behaviour within the continuous improvement of manufacturing processes. Factors that influence the individuals' decisions to engage with additional tasks include culture, nature of work and work-life balance. Boosted leadership at the supervision level leads to a positive outcome in the perception of the workers' own role in the team. Van and Nafukho (2019) explored the antecedents and consequences of employee engagement and proposed a framework with three antecedent clusters included the internal environment, job-related and employee-related factors, and employee engagement with three outcome clusters: intra-role behaviours, extra-role behaviours and personal development and growth. As a result, turnover engagement, job performance, organizational commitment and organizational goal attainment were found as the key employee engagement consequence attributes. Teryima et al. (2016) investigated motivational factors determining employee commitment and performance enhancement, finding that intrinsic, extrinsic and social motivation have a good relationship with employee commitment and performance enhancement in manufacturing companies, while the lack of motivational incentives leads to employee frustration.

Ghobakhloo (2020) propose a model for determinants of the adoption of smart manufacturing. Financial resources, management support and strategic road mapping for digitalization are the fundamental basis for employees' qualification. The existence of three determinants is necessary for developing and enhancing human resource skill sets required by smart manufacturing. Meanwhile, employees' qualification for manufacturing digitalization is a basis for other conditions for the adoption of smart manufacturing digitalization maturity, openness to change and seamless integration capability. Raj et al. (2020) examined barriers to the implementation of Industry 4.0 technologies in the manufacturing sector. There are 15 barriers identified in this study, where "lack of a digital strategy alongside resource scarcity" appeared as the most eminent barrier. Most of the 
barriers are related to communication challenges between employees or the information flow between different management levels. There is a long list or reason for those barriers, such as: resistance to change; lack of internal digital culture and training; challenges in ensuring data quality; lack of digital skills; lack of infrastructure; lack of standards, regulations and forms of certification; disruption to existing jobs; inequality; the low maturity level of the desired technology; risk of security breaches; and challenge in valuechain integration. The barriers can also be an outcome from the lack of clarity regarding the economic benefit, as well as high investment in Industry 4.0 implementation.

The reason for difficulties in the diffusion of technological innovation is also based on the lack of coordinated national policies on Industry 4.0, which prevents manufacturing companies from the full experience of the Industry 4.0 revolution. Connected enterprises in smart manufacturing can benefit employees by: informing them about production requirements and responsibilities to reduce waste, minimizing miscommunication, increasing their safety and ergonomics and identifying new business opportunities and markets (Mittal et al., 2020). According to Freddi (2018), due to changes in the labor market, manufacturing demands new types of skills in relation to service provision and software development. Industrial companies will become more focused on service provision and augment the employment dedicated to this. The software applications incorporated in products and processes tend to be developed internally and lead to a growing demand for software development competencies. According to Gillani et al. (2020), communication technologies support interactions among employees and contribute to the flow of information and knowledge. Collaboration, coordination and flexibility of work with lean structures can lead employees towards autonomy and the ability to resolve issues responsively; employees face a transition role from operators to problem solvers. Integration of technologies also requires employees to be multi-skilled and demands job rotation as well as cross-functional and autonomous teams.

Two research questions were derived from the literature reviewed.

2.3.1 Research questions.

$R Q 1$. How are soft management practices and employee behaviours influenced by the adoption of digital technologies in lean manufacturing plants?

$R Q 2$. How do soft management practices and employee behaviours relate to the emergence of digital waste?

\section{Method}

According to Yin (2014), case study research is the most suitable type of research for howtype questions. The objective of this study is analytic generalization and not statistical generalization (Yin, 2014), so investigation of two case studies was structured. The research follows a multiple case study design with the intention not to be limited in generalizability by single-case conclusions (Voss et al., 2002). Two companies were selected for semistructured interviews (Table 2). The unit of analysis in this research is the manufacturing company (Rowley, 2002). Criteria in the selection of cases included ability to observe transparently, polar type of cases and clarity with a research phenomenon, following the recommendation of Yin (2014). First of all, both companies have a long history of lean method adoption and are currently embarking on a supplementary digital adoption process, with a view towards digital transformation. Secondly, the companies are going through the digital transformation phase. In Company 1, the whole manufacturing process is being digitalized. In Company 2, the digitalization process is focused on a particular production 
IJLSS

14,1

10

line. Thirdly, heterogeneous approach was used for selection of cases - even though they are sister companies and operate under the same brand, they are in different countries and focused on different production items (Ciano et al., 2020). The differences between the companies were expected to produce different results from two cases and follow the replication logic applied for case studies (Voss et al., 2016). A case study protocol was used at the data collection stage, which helped to achieve higher reliability (Yin, 2014). With Company 1, data was collected through physical face-to-face interviews, while with Company 2 the interviews were virtual through the Zoom application, because of social distancing restrictions. Zoom interviews were recorded - after permission from participants - and then transcribed. The transcripts, along with notes taken during and after each interview, were collected and stored in a devoted database (Kassem and Staudacher, 2021). Interview questions were aimed to reveal what soft factors and employee behaviours are influenced by the digital transformation in LM plants and which ones relate to digital waste (see Appendix). Open coding was used to analyse interview notes, and the codes were grouped and categorised (Elo and Kyngas, 2008). The content analysis performed to identify patterns to contribute to the development of the theory. Indeed, transcripts together with company YouTube videos, notes, ensured data triangulation (Duriau et al., 2007). The coding process has been conducted manually by the authors, to ensure inter-code reliability (Duriau et al., 2007; Kassem and Staudacher, 2021).

\section{Results}

\subsection{Company 1}

The company is based in Sweden. Production focuses on crash boxes made from aluminium. The plant operates $24 \mathrm{~h}, 7$ days a week. There are around 30 blue-collar employees working per shift, with four levels of management: the plant management team, operations management, production unit management and team leaders. Most of the raw materials (aluminium profiles) are supplied by a sister company (from the same brand). Product design is developed by the customer, focussed on premium cars. In most cases, customers pick up their products from the factory. In 2010, there were only two computer numerical control (CNC) machines operating on the shop floor. In 2015, active process automation began, and the number of CNC machines increased by 15 , accompanied by 50 robots working together now with operators. The goal of the company is a full adaptation of manufacturing employees to automation processes. Currently, approximately half of the operators have adapted to work with $\mathrm{CNC}$ machines successfully, while another $50 \%$ are in the process of adaptation.

\subsection{Company 2}

The company is based in Norway. Production focuses on aluminium bumpers for cars. The production line operates $135 \mathrm{~h}$ per a week with two operators per shift. There also four levels of management: the plant management team, operations management, production unit

Table 2.

Companies participating in the study

\begin{tabular}{llll}
\hline Country & Company & Title & Interview type \\
\hline Sweden & Company 1 & Plant manager & face-to-face \\
& & Production manager & face-to-face \\
& Team leader & face-to-face \\
Norway & Company 2 & Production unit leader & via Zoom \\
& & Process operator & via Zoom \\
& & Operator/shift leader & via Zoom \\
\hline
\end{tabular}


management and team leaders. Most of the raw materials (aluminium profiles) are supplied by the sister company as well. There are two main customers; product design is developed in cooperation with them. The new production line, settled with robots and CNC machines, was completed in 2014. The product is not touched by the operator during the production process. Education of operators is an ongoing process and leads to high dependency on highly skilled professionals. This information is summarized in Table 3.

Table 4 is a summary of interview results. The upper part of the table evaluates lean and TQM soft management practices based on the responses of the plant managers and production unit leaders. The lower part of the table, based on responses of shop-floor employees (the production manager, team leader, process operator and operator/shift leader), covers employee behaviours evaluation. Responses are marked with " $x$ " as votes - symbolizing the nature of the response in a positive, neutral or negative ways. For example, two responders from different companies confessed that digital transformation within their organizations had a positive impact on top management and leadership practice. Another examples, is a customer focus practice, when digital transformation had no impact on it, according to two responders. The last examples creativity employee behaviour, that experienced negative influence from the digital transformation, based on four responses. Further, responses discussed in Section 5, supported with quotes from the responders.

\section{Discussion}

In this section, variables from the model were sorted based on popularity of responses and the nature of responses. Section 5.1 presents responses to $R Q 1$; Section 5.2 presents responses to $R Q 2$.

\subsection{Soft management practices (lean and total quality management), employee behaviours} and digital transformation

In $R Q 1$, it was attempted to discover what soft management practices and employee behaviours are influenced by the digital transformation in LM plants. Based on the interview responses, 29 variables were influenced in positive or negative ways by the adoption of digital technologies (see Table 4). Other variables were not influenced in any way by the digital transformation and remained neutral. Finally, several variables were hard to evaluate for the influence by the digital adoption, due to very different responses and a lack of consistency in those answers. Next follows a discussion of each set of variables.

5.1.1 Positive soft management practices (lean and total quality management).

5.1.1.1 Top management and leadership. The top management team support is essential in firms' digital transformation (Wrede et al., 2020). According to Porfírio et al. (2021), democratic leadership style has a high impact on strategic management processes at

\begin{tabular}{llrr}
\hline Employees & Company 1 & Company 2 \\
\hline & Plant & Production line \\
Digital Transformation & CNC machines, robots & CNC machines, robots \\
Number of employees before January 2020 & 190 & 13 & 9 \\
Number of employees after January 2020 & 150 & 37 & Table 3. \\
Average age of employees & 40 & 5 & Summary of the \\
Male Employees & Majority & 4 & companies' \\
Female Employees & Minority & & employees \\
\hline
\end{tabular}

Significance of employee behaviours 
IJLSS

14,1

12
Table 4.

Influence of employees' soft management practices (lean and TQM) and behaviour in the midst of digital transformation

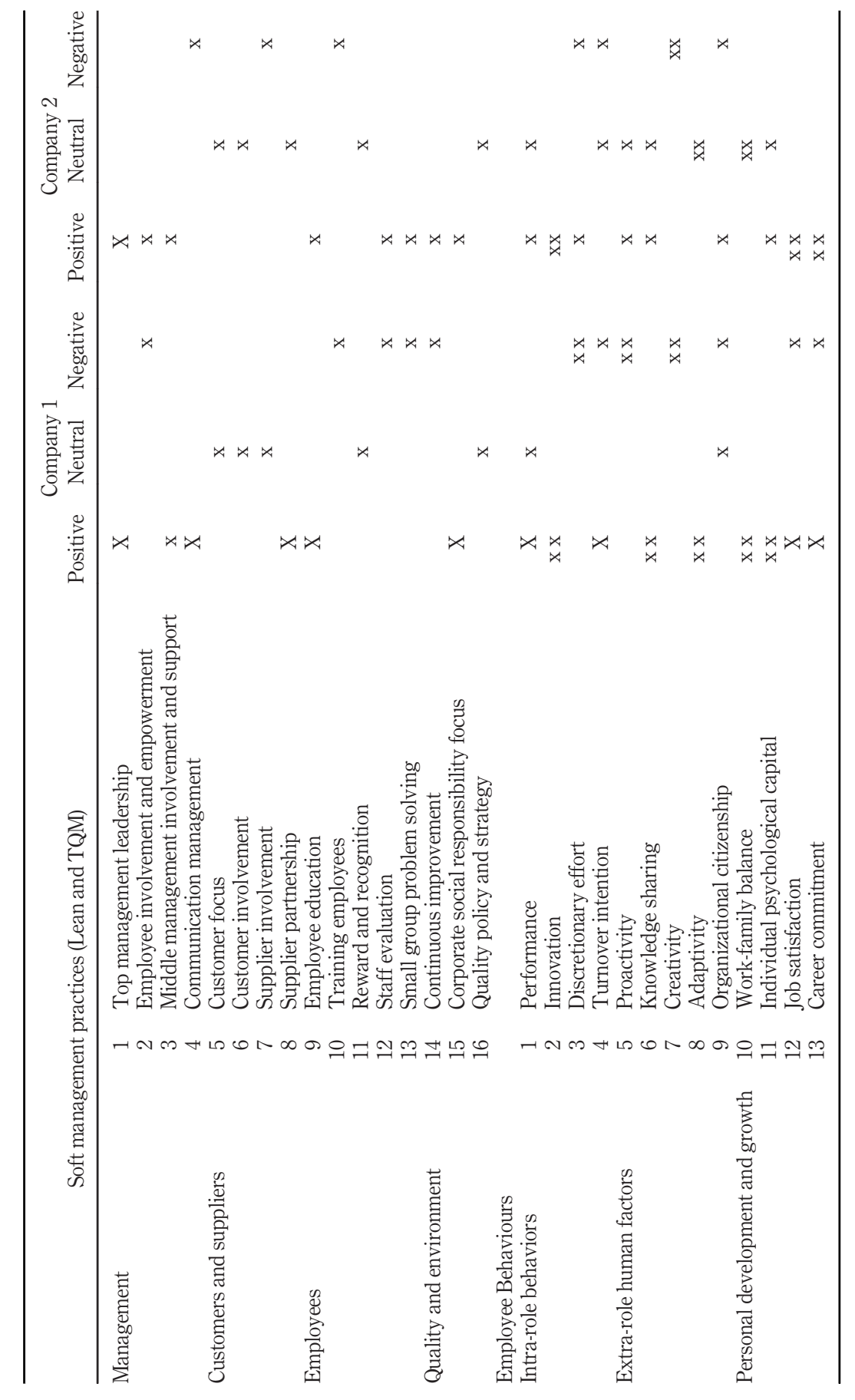


advanced stages of digital transformation. Company's mission shared - through effective leadership - among the staff and employees, is crucial to mobilize actions towards digital transformation. In this study, top management (in both companies) acts as a role model and defines the vision for change and goal setting in digital transformation. In Company 1, communication of the goals to the rest of the plant employees happens four times per year through meeting with employees in a conference format. Company 2 management also receives explanations of the processes from the top management on a regular basis.

5.1.1.2 Middle management involvement and support. Proactive digital transformation requires delegation of critical aspects of activities - to middle-level managers - who are in direct contact with customers and other actors in the digital ecosystem and who have direct knowledge of global markets. The middle managers need to deal with the increased speed of change, innovative culture, internal knowledge absorption, dynamic external environment and an internal organizational identity that is subject to frequent change in the transformation process (Volberda et al., 2021). In Company 1, team leaders are the mediators between the production employees and management. They are very supportive at the stage of transformation. The same happens in Company 2, where the manager reports that "it is easier to gather information about the process and the quality of the production" and support employees by being able to use common data gathered on one computer.

5.1.1.3 Employee education. Albukhitan (2020) discusses challenges of manufacturing industry in digital transformation where "absence of relevant knowledge" is one of the biggest challenges for employees. To mitigate such challenges, it is necessary to consider collaborating with external consultants or hiring new employees. The responsibility for digital technologies adoption should be a common goal for the whole organization and not limited to just a few employees or departments. For Company 1 management, education is an important part of automation transformation. Currently, most of the trainings are internal for $\mathrm{CNC}$ operators. There are two-week external trainings for mechanics and employees who set up the machines. Sometimes suppliers organize trainings. Company 2 is set up for internal schooling and collaboration with public schools. "It has been big improvement in collaboration between industry and the schools to set up required programs needed for the industry." Now there is a new set-up for the operators.

5.1.1.4 Corporate social responsibility focus. Raweewan and Kojima (2020) discuss the successful collaboration project between with SIIT-DENSO and undergraduate and graduate students. The students were trained through Lego car assembly with digital tools to gain cognitive and non-cognitive skills in lean transformation. By the end of the project students learned how to detect muda with quantitative visualization and eliminate them and then simulate physical design to analyze the sensitivity of process design. In Company 1 , digital transformation has a positive influence on synergy with their external communities, such as the local employment government entity. The HR manager defined the expected skills and requirements for the $\mathrm{CNC}$ operators to employ local people. Company 2 is also perceiving a positive influence of digital transformation on communities, through the employment opportunities for the region and collaboration with schools.

5.1.2 Neutral soft management practices (lean and total quality management).

5.1.2.1 Customer focus. As the world begins to engage with digital technologies and work differently, industries started to cope up with the increased customer demands mainly focus on three core characteristics: instruments, interconnection and intelligence (Buer et al., 2021). Both companies have quite neutral responses regarding the digital transformation as a booster of customer importance for quality improvement. According to Company 1, customer satisfaction is a priority to stay competitive on the market. Production automation 
IJLSS

14,1

is motivated by the competition, rather than by customers' specific requirements. Company 2 agrees that communication with customers has become much easier:

We have all the tools to communicate efficiently. We have a very good traceability system on each part we produce. But I'm not sure if it is connected to robots or CNC machines.

5.1.2.2 Customer involvement. Digital technologies allow businesses to alter their value creation activities by enhancing user experience and improving customer relationship management. The benefits from digitalization - which includes customer experience improvement - can be considered one of the forerunners of value generation (Truant et al., 2021). Neither company expressed a confident opinion about customers involved in the digital transformation of the company. In Company 1, customers are involved in the control stage, through the audit checks. Their main priority is to confirm if the agreed processes and standards are implemented appropriately. At the same time, customers are acting as investors where the tools are customer owned. Company 2 could not reflect on customers' involvement in the digital transformation of the company.

5.1.2.3 Reward and recognition. According to Saraiha et al. (2021), the organization should focus on employees' training and reward to ensure the employees' performance can be increased. Reward system among manufacturing employees has also positive effect on employees' motivation (Din et al., 2021). In both cases, it was hard to evaluate whether digital transformation has had an influence on rewarding and recognising employees for their contributions, because in both companies the practice is not common. In Company 1 , there are a few meetings per year where all the employees meet together in a hall and summarize the general productivity of the plant. Company 1 also holds a Christmas dinner. There is no system for individual employee rewards or recognition of their contributions. Company 2 does not give rewards for individual achievements either.

5.1.2.4 Quality policy and strategy. According to Volberda et al. (2021), the digital transformation requires the creation of new cognitive schemes, the development of fundamentally new routines, and the redesigning of the organizational form. In both cases, it was hard to evaluate if digital transformation has a positive influence on corporate polices and strategies focusing on quality. Company 1 does have a set of policies. "Increasing number of CNC machines and robots has no influence on new policies and strategy development," one manager said. There was no clear observation or feedback from Company 2 if digital transformation has a positive influence on corporate polices and strategies.

5.1.3 Negative soft management practices (lean and total quality management).

5.1.3.1 Training employees. According to Mokudai et al. (2021), the high level of digitalisation is associated with multi-tasking jobs, decentralised decision-making at the team and flat hierarchy. Consequently, interconnected production processes impact the autonomy enjoyed by workers. According to both companies, digital transformation has no influence on job rotation and cross-functional training programs. In Company 1, rotation was and continues to be a common attribute within each division. However, there is no rotation within the different divisions. In Company 2 , there is some job rotation, but more is needed. "We need more flexibility from employees to increase competences of the employees."

5.1.4 Other soft management practices (lean and total quality management). There were no consistent answers related to employee involvement and empowerment, communication management, supplier involvement, supplier partnership, staff evaluation, small group problem-solving or continuous improvement. Those variables were excluded from further analysis. 


\subsubsection{Positive employee behaviours.}

5.1.5.1 Innovation. The industry practitioners should not underestimate the employee's digital literacies in the digitalised workplace and organisational culture that is rich in innovations. Therefore, organisations would have to boost employees' digital literacies linked with workplace digitalisation and cultivate a strong innovative culture, to strengthen employee commitment (Chan et al., 2021). The technologies can create innovations through innovative activities and employment quality (Choi et al., 2020). Company 1 employees agree that there is a potential opportunity to perform tasks in a new way with the digital transformation process. Using $\mathrm{CNC}$ machines and increasing number of robots at the shop floor allows them to increase productivity and diversify the tasks of operators. "With the help of robots there is a possibility to move parts during the work in a different way." Company 2 employees acknowledged innovation through the new way of material handling technology - autonomous equipment that can deliver items to a specific place or pick them up from any place. "With drones the warehouse is a different place." "We don't do any lifting anymore," was mentioned by the employee with 14 years of experience in the plant. Daily routines also changed the focus from implementation to control: "Robots don't have eyes, and this is the biggest risk."

5.1.5.2 Knowledge sharing. Digitalisation of manufacturing is going along with challenges for employment, work organisation and working conditions. Extended knowledge of digitalisation and its consequences at the workplace can lead to sharing knowledge that can help guide future action (Haipeter, 2020). According to Kim and Park (2021), a knowledge sharing culture has a positive impact to interpersonal trust, knowledge sharing behavior and organizational learning. Employees from both companies agree that there is a potential opportunity to learn from colleagues in the digital transformation process. In Company 1, employees are encouraged to consult with management about any difficulties related to work with robots. Daily peer-to-peer learning is a common practice among $\mathrm{CNC}$ operators. The general training can take up to one week, when the new employee learns from observation, standing next to an experienced operator. In Company 2, employees share an idea that they can improve each other through feedback. "We discuss problems, and we share an experience or ask for help. This is a culture in the company."

5.1.5.3 Work-family balance. According to Choi et al. (2020), the work-life balance is improved due to technological improvement and its significant implication in terms of labor innovation. Employees from both companies agree that the digital transformation process has a positive influence on work-family balance. Meanwhile, employees from both factories believe that such a balance was always an important part of the company's culture. "Norway is a family-oriented country. The company always cares about an employee's health or family circumstances. There is no negative influence from technologies because of technologies."

5.1.5.4 Psychological capital. According to Lei et al. (2020), transformational leadership style plays a big role in employees' positive psychology sources and firms' innovation capability via the mediating role of employees' positive psychological capital, namely, selfefficacy and optimism. Wang and Han (2020) suggest to increasing employees' understanding and identification of their work for gaining a sense of efficacy, as well as enhancing employees' sense of belonging in the process of technological change. Employees from both companies agree that the digital transformation process has a positive influence on self-efficacy, optimism, hope and resilience at work in general. According to the interviewee in Company 1 , there is no stress related to the robots or $\mathrm{CNC}$ machines. Instead, there a positive feeling about expecting the team to increase in number. There is also a positive attitude about the work and ongoing digital transformation processes. A Company

Significance of employee behaviours 
IJLSS

14,1

2 employee say she feels positive and less tired when she comes back from work. However, another employee mentioned that there is a fear of being replaced by the machines. "This is a natural fear. It always has an influence on psychological condition, somewhere in the back of the mind."

5.1.5.5 Job satisfaction. Manufacturing enterprises experiencing technological change must promote psychological ownership of the improvement of employees' job satisfaction in the process of change (Wang and Han, 2020). Employees from both companies agree that the digital transformation process has a positive influence on job satisfaction. In Company 1, there are 48 operators, creating a diverse team. The management position involves communication with people more often, which is interesting. However, some standards require a manual job, instead of previously automated processes, which sometimes leads to stress. Another employee agrees that the job environment is very challenging and there is big room for improvement. This is what has created the most comfortable atmosphere and brings a high job satisfaction. Company 2 employees believe that their work now with new technologies is more interesting:

Having ownership of your job brings you job satisfaction. It should be a match between an employee's desire to learn and the request to learn something new. If the right person is doing the right task, then it is positive, one employee says.

5.1.5.6 Career commitment. Manufacturing employees may feel stress related to digitalization and growing job demands. The engagement into the job crafting can lead behaviors to get more resources to meet their career goals and make better career plans (Xu et al., 2020). Employees from both companies mostly agree that the digital transformation process has had a positive influence on individual career goals. A Company 1 employee aims to become a member of the top management team. He can picture himself reaching his goal through hard work and fast learning of company policies and trainings. Another employee has no individual career plan and no connection between the career plan and the number of robots on the shop floor. Employees from Company 2 already experienced career growth due to technology adoption.

5.1.6 Negative employee behaviours.

5.1.6.1 Creativity. According to Sun et al. (2020), manufacturing industry is still heavily relying on the import of core technologies, hardware and equipment. Instead, government and manufacturers should attract more attention on skilled workers to boost creativity along with productivity and innovation in manufacturing industry. According to Ogbeibu et al. (2021), digital task interdependence and disruptive technology have positive effects on team creativity willingness - it drives the exchange of creative ideas in work teams. There is no positive evidence in either company for the potential or opportunity to be creative with the digital transformation process. Company 1 employees associated it with a strict company standard that it was required to follow. "No, there is no potential to be creative. All the activities are prescribed in the company manual and must be followed in accordance" and "The processes are prescribed in detail by the company's standards, which are compulsory to follow. There is no or only low potential for creativity." Company 2 employees have similar limitations on creativity:

We have limits on how the product is supposed to be and we don't have much room for creativity unless it is discussed with management. Instead, we follow the standards defined by the customer

and "Being part of the system, it is important to be focused. However, it is hard to be creative." 
5.1.6.2 Discretionary effort. According to Permana et al. (2021), employees with a high engagement are likely to give more discretionary effort at work. The high engagement also impacts higher productivity, profitability, customer service, reduced turnover and safety incidents. There is no positive evidence in either company for the potential opportunity to work harder with the digital transformation process. A Company 1 employee believes that there is no potential for employees to work harder without a risk to their health. Another employee believes that a factory employee defines the level of effort to put in while performing the work himself. It cannot and should not be influenced by the robots or the advanced technologies offered by CNC machines. In Company 2, one of the employees believes that they can be more efficient, because many things have been designed for that. Such as "the shop-floor system we use from Lighthouse. It counts the items from production to know the exact number of items we produced." "Not sure if we can work harder with technologies, but we are definitely more efficient. And the potential to make it even more efficient is there." Another employee emphasized the lack of stability associated with digital transformation - "It's still a bit unstable. A new way of working. We need more hardworking people to make the production stable, many little things together to make it work."

5.1.6.3 Turnover intention. According to Choi et al. (2020), the Industry 4.0 rises concerns of labor forces being replaced by technology - job changes by advanced technologies, such as artificial intelligence and the internet of things. Physical labor as well as intellectual labor will be replaced by technologies. Some fear is associated with the job due to the digital transformation process on the plant. Company 1 employees have a little fear of competition. Another employee does not fear that the increasing popularity of technologies will make them lose their jobs. "Robots cannot replace the people." In Company 2, one of the employees asserted the competitive advantage of robots - "Robots don't get sick." However, the employee said that the big fear was only at the beginning. Now, fewer people are able to perform more work, and the company has an increased number of orders. Two people are able to do a task that was assigned to six people earlier. Another employee has a bigger fear in comparison to her colleague:

Oh, I fear it. I believe I'm from the generation that is adaptive to the technologies. Nevertheless, they are beginning to surpass me. Now, you have to know the system and processes before you even start working.

5.1.6.4 Proactivity According to Zangiacomi et al. (2020), proactivity in digital transformation requires to foresee a proactive involvement of human resources. The ability in perceiving the path towards digital transformation is also in the adoption of proactive approach in defining the resources, processes and procedures involved in the process. There is no clear evidence in either company for the potential or opportunity to predict problems and challenges at the workplace with the digital automation process. Company 1 employees believe that most problems stem from the daily routines. Most of them are caused by human mistakes; no robots can predict them. "Robots aim to help humans in completing the tasks in a quicker and safer way." In Company 2 , there is doubt about predictions:

Robots can stop working, and we can't predict it. We have counting parts, when it gets close to change the tools. When twelve thousand pieces are produced, the tools have to be changed. Otherwise, it will cause defects. The machine makes an alarm when the change is needed. Before it was not possible to predict mistakes until one can notice defects in the products, one employee says.

Another employee shared:

If people trained, yet it is possible. However, in our plant we have senior employees that have been employed by the factory since they were 17 years old. They might feel some resistance to 
IJLSS

14,1

technologies, taking into consideration their experience of 40 years. In a complex system on the operative level, it can be hard to predict problems. However, some operators are very proactive. When they see a potential problem, they mention it. But not when it comes to predictive operators. It can be too technical.

\subsubsection{Other employee behaviours.}

5.1.7.1 Performance. According to Dutta et al. (2020), manufacturing sector requires rapid implement of digital technologies to improve performance and remain competitive in the dynamic market. The companies can improve the performance by defining the organisational culture that supports their digital strategy. In that case, value activities can be boosted through the business digitalization (Martínez-Caro et al., 2020). There was no common opinion about the potential opportunity to work better with the adoption of digital processes. One employee from Company 1 states that there are no extra opportunities to work better with a progressive use of robots integrated into the work of CNC machines. "Robots are the sign of future, but the work depends on the factory employee and personal motivation." However, another employee from the same company states that shop-floor robots have improved safety by decreasing the risk of injury. Manual work leads to tiredness, which also decreases with more robots. Company 2 also has a difference in opinions. One of the employees observes a difference - "It is not fully automated yet, but the collaboration with robots helps. Compared with 14 years ago, the performance is improved." Another employee says:

There is opportunity, but there are also job cuts. Machines bring an advantage, but we must always involve the human side in the equation. Not well-trained employees and poor knowledge of system management can lead to failure. Heavy lifting is done by 20 robots we have now. Nevertheless, operators must know how to operate new machines to keep the operation on an optimal level. That requires education, training and time to make them feel comfortable and deal with new robots and $\mathrm{CNC}$ machines. We still have a long way to go to achieve that 4.0 that everyone is talking about. We are not even close yet. We require human input and human judgement to improve what we can until systems can take over the instinct of a person.

5.1.7.2 Adaptivity. There are different strategic frameworks that evaluate digital readiness and help organizations transformation. It is important to deal with mindset change - critical barrier to success in organizational change effort - with a focus on rapid adaptivity (Jones et al., 2021). According to Siedler et al. (2021), adaptivity along with efficiency is an outcome from new possibilities boosted by manufacturing digitalization. There was no common opinion about the potential opportunity to easily adapt to the digital transformation process. In Company 1, one employee states that all the challenges and new tasks are easy to adopt to with the help of internal company policies and guidelines. Another employee shares that the company's standards are hard to learn quickly, so adapting can take up to two months. However, robots can play a big help in this process. In Company 2, there is an opinion that adaptability to digitalization changes from generation to generation. The Generation of 2000 [Millennials] will find it easy, those of 2015 [Generation Alpha] will find it unbelievably easy. The rest will struggle. Another employee shared a challenge of past experience:

It was hard at the beginning. We had no time. We installed the new line and it was learning by doing. We wanted more time to learn. After a while it became easier. It was in 2016 and it took one year to learn. But the line was built in steps, the line was not completed, and we were not prepared up to 2017.

5.1.7.3 Organizational citizenship. Singh et al. (2020) studied shop floor employees' performance in the manufacturing industry experiencing technological disruption. The results indicate that high-performance work system is positively associated with 
organizational citizenship behaviour. There was no common opinion about the potential opportunity to encourage employees to form group and implement assignments together during the digital transformation process. In Company 1 , besides the scheduled meetings, there are random meetings about quality from time to time. Yet employees have limited opportunities to meet in groups besides the regularly scheduled meetings, lunch and two coffee breaks each shift. There is no intensive communication. Instead, there is isolation during work time. In Company 2, one of the employees stated that there is a lack of people gathering because there are fewer people. Another employee had an opposing point of view:

\section{Significance of employee behaviours}

Employees are often invited to join and participate in the implementation activities. They can try and get to know the technologies. They give input on what can be better or if they need extra training. When we set up a new line, we invited people who will work on the line to see the equipment. At least one person from the team was invited into the project meetings before the new equipment launched.

\subsection{Soft management practices (lean and total quality management), employee behaviours and digital waste}

With $R Q 2$ it was aimed to discover what soft factors and employee behaviours relate to digital waste. The definition of digital waste proposed by Powell et al. (2018) was followed in this study: any non-value-adding digital activity to personnel, materials, machines, methods or measurements in LM companies influenced by digital technologies. Company 1 and Company 2 have had a recent massive increase in CNC machines and robots, which are digital technologies, and the adoption of those technologies is a digital activity. The variables from Table 4 that are positively influenced by digital transformation are valueadding, so they will not be investigated further for the digital waste detection due to their positive influence. Attributes that are neutrally or negatively influenced by digitalization are in focus in responding to $R Q 2$.

5.2.1 Soft management practices (lean and total quality management) and digital waste. 5.2.1.1 Customer focus. There is no clear evidence that digital transformation has a nonvalue-adding activity to methods or approaches to how customers are treated. Communication with customers has a positive tendency - it is efficient and driven by high competition. There were no negative reflections about digital transformation, yet there is no positive feedback to show that the relationship with customers is strongly associated with digital transformation. The relation of digital waste and customer focus requires further investigation.

5.2.1.2 Customer involvement. The involvement of the customer in the control stage diffuses control over all the related activities, including digital transformation. It could be done indirectly or unintentionally, yet control remains part of the process. Consequently, customer involvement in the digital transformation process would be rather perceived as a potentially value-adding activity and prevent the obvious possibility of digital waste.

5.2.1.3 Reward and recognition. In both companies, there was no strong basis for the personal evaluation of employees' success and efficiency. There was also no practice of giving individual rewards for personal achievements. With the adoption of digital technologies, the situation has not changed. Yet the potential to evaluate progress in each employee's work is higher. It is easier to track which employee worked with a particular robot or $\mathrm{CNC}$ machine and how efficient that work was compared to that of other employees. Tracking such information can be a value-adding activity to operations management for strategic decision and detection of room for continuous improvement. It was concluded that the lack of reward and recognition in the digital transformation process can potentially 
IJLSS

14,1

relate to digital waste as a non-value-adding digital activity to people in LM companies influenced by digital technologies.

5.2.1.4 Quality policy and strategy. It is hard to reflect on whether digital waste is connected to corporate policies and strategies focusing on quality in the digital transformation stage. On one hand, strict policies are a fundamental part of the disciplines and regulations that are easy to learn and implement in the challenging period of digital transformation. On the other hand, employees are the key resources that can lead to improvements based on their personal experiences and needs in a better working environment. The fact that both companies are very strict about their policies, and that an increasing number of $\mathrm{CNC}$ machines and robots have no influence on new policies and strategies development, could be the result of high-quality policies and lack of a need changes to them. The relation of digital waste and the quality policy and strategy factor requires further investigation.

5.2.1.5 Training employees. The lack of cross-divisional job rotation limits the flexibility of employees and increases the dependency on a particular specialist, who, for example, is familiar with CNC machines or robot programming. In a critical situation, this can influence the efficiency of the production process. Consequently, it was perceived the lack of employee training factor (with a focus on cross-divisional job rotation) in digital transformation process as a non-value-adding digital activity to people and methods in LM companies influenced by digital technologies.

5.2.2 Employee behaviours and digital waste.

5.2.2.1 Creativity. Creativity is limited by prescribed rules and standards that are compulsory to follow. Rejection of rules and standards could lead to chaos, so they are an essential and non-negotiable aspect of the manufacturing production process. It was assumed that there is no clear evidence of digital waste in creativity since the lack of creativity in this circumstance can be a value-adding digital activity to methods and measurements in LM companies influenced by digital technologies.

5.2.2.2 Discretionary effort. It is hard to reflect on whether digital waste is related to the discretionary effort of employee behaviours in digital transformation. On one hand, employees have the potential to be more efficient, yet they question their ability to work harder without putting themselves at risk to their health. Lack of stability associated with digital transformation is another argument that prevents extra hard work. The relation of digital waste and discretionary effort behaviour requires further investigation.

5.2.2.3 Turnover intention. The presence of fear (of losing one's job) in different forms and stages of digital transformation exists. Some employees even compared themselves to robots in positive and negative ways, recognising that robots never get sick unlike humans, yet they cannot fully replace people. The fear of losing their jobs can be a driver for employees to work harder and be more devoted to work. Meanwhile, the feeling of fear at work can cause a negative influence on life-work balance behaviour and psychological capital. It was assumed that there is a potential of digital waste in relation to turnover intention since the fear of losing one's job in the digital transformation process is more likely, and this can be a non-value-adding digital activity to people in LM companies influenced by digital technologies.

5.2.2.4 Proactivity. Some employees believe that robots are there to help to complete the task (not to predict problems), which might justify the limited perception of robots' potential on the shop floor. Other employees share that they cannot predict when robots will stop working and why. At the same time, positive examples include defects prediction with CNC machines and the alarm system that indicates when tools need to be changed. Yet individual proactivity of employees can still lead them to predict and prevent challenges in a 
production process. It was assumed that there is an actual potential to utilize robots and $\mathrm{CNC}$ machines so that shop-floor problems become more predictable. Ignoring that potential is a non-value-adding digital activity to machines and methods in LM companies influenced by digital technologies.

5.2.3 Other employee behaviours and digital waste. Performance, adaptivity and organizational citizenship attributes were excluded from further analysis of their relation to digital waste, because of nature of answers that are shared between positive and neutral. It was assumed that digital transformation is mostly a value-adding activity in relation to performance, adaptivity and organizational citizenship of employees. Consequently, it was not suspected that further digital waste exists in relation to performance, adaptivity or organizational citizenship attributes.

\section{Conclusions}

\subsection{General}

In this paper, we investigated 29 soft management practices (Lean and TQM) and employee behaviours under the influence of digital transformation in LM plants. The top management leadership, middle management involvement, employee education and corporate social responsibility focus factors were observed as positively influenced factors in the digital transformation process. Among employee behaviours, the positively related variables are innovation, knowledge sharing, work-family balance, psychological capital, job satisfaction and career commitment. The training employees' factor was negatively influenced by digital transformation. Creativity, discretionary effort, turnover intention and proactivity were also negatively influenced attributes among employee behaviours in the process of digital transformation. Some factors remained neutral, such as customer focus, customer involvement, rewards and recognition, and quality policy and strategy. A number of soft factor and employee behaviours remain undiscovered due to inconsistency of interview responses and challenges in generalizing from those reflections.

It was also discovered what soft factor and employee behaviours relate to digital waste as any non-value-adding digital activity to people, materials, machines, methods or measurements in LM companies influenced by digital technologies (Powell et al., 2018). The potential for digital waste was detected in the reward and recognition factor and training employees' factor among soft factors, as well as in turnover intention and proactivity attributes among employee behaviours. It was detected no potential for digital waste in the customer involvement soft factor or the creativity attribute of employee behaviours. Attributes that need further investigation to discover their relation to digital waste include customer focus, quality policy and strategy soft factors, and the discretionary effort attribute of employee behaviours.

\subsection{Theoretical contributions}

There were several studies discussing the impact of digital transformation on soft lean management practices, soft factors for TQM implementation, and employee behaviours. The unique theoretical contribution of this study is an ability to review those important variables all together and prioritize the focus of importance among them in the organization. This study contributes to the discussion initiated by Georgiev and Ohtaki (2019) on successful soft factors for TQM implementation. In addition, it adds to Gaiardelli et al.'s (2019) discussion of soft lean management practices during digitalization. In this study, soft factors were discussed in the context of digital transformation. The study also contributes to the work of Van and Nafukho (2019) by supplementing the discussion of employee behaviours. In this study, employee behaviours were discussed in the context of changes 
IJLSS

14,1

within the organization experincing the digital transformation. The study also contributes to the work of Romero et al. (2019d) and Alieva and Haartman (2020) on digital waste, as well the discussion of lean waste (Womack, 1990). Specifically, the study contributes to the lean literature with a focus от lean waste (muda) and employees (people) - as one of the pillars of lean. Discussion of digital waste is one of the major contributions of the study, where it is expected to be considered as a part of muda in the context of digital transformation.

\subsection{Practical contributions}

This study helps to guide practitioners through the digital transformation process. It can help a management team identify what aspects of employee behaviours need to be considered for successful digital transformation. Employees possible can experience challenge to express their creativity or establish secure environment for the knowledge sharing in a phase of digital changes within the company. It is a responsibility of management to identify potentially vulnerable employee behaviours in organization and establish the secure and smooth transition overcoming all the potential barriers related to those behaviours. It guides the management team to prioritize soft management practices (lean and TQM), to be considered during the digital transformation. For example, staff evaluation practice might become one of the most relevant practices in the stage of digital transformation within the company. It might lead towards objective assessment about the speed, path, and approach of change. Quality policy and strategy is another practice that might be prioritized for successful digital transformation, where the number of policies could be reconsidered or replaced by new one due to different approach of managing tasks in a new circumstance. Finally, the study motivates practitioners to be aware of digital waste as a part of the lean waste during the process of digital transformation. Being aware of digital waste implies careful consideration when integrating digital tools into otherwise traditional lean management. Deliberate monitoring of digital tools usage can lead to their sustainable and efficient utilization, that may protect from unwilling digital waste generation. Consequently, it will protect practitioners from some of non-value-adding activates and create the value instead of waste.

\subsection{Limitation and further study}

Further research could discuss hard lean management practices as well as physical work environment characteristics proposed by Gaiardelli et al. (2019) in the context of digital transformation. While our model discussed employee behaviours in the context of digital transformation, future studies might be extended through the discussion of external environments, job-related factors and employee-related factors (Van and Nafukho, 2019). The study was limited by investigating only two companies. Due to the small number of participants, it was hard to evaluate all the variables in a consistent way. In further studies, it is suggested to increase the number of companies and people participating in interviews.

\section{References}

Adam, C., Aringer-Walch, C. and Bengler, K. (2019), "Digitalization in manufacturing - employees, do you want to work there?", in Bagnara, S., Tartaglia, R., Albolino, S., Alexander, T. and Fujita, Y. (Eds), Proceedings of the 20th Congress of the International Ergonomics Association, IEA 2018, Advances in Intelligent Systems and Computing, Vol. 825, pp. 267-275.

Agostinho, V. and Baldo, C.R. (2021), "Assessment of the impact of industry 4.0 on the skills of lean professionals”, Procedia CIRP, Vol. 96, pp. 225-229. 
Agus, A. and Selvaraj, R. (2020), "The effects of people- and technical- oriented TQM on productivity: the mediating role of production performance", International Journal of Business and Society, Vol. 21 No. 1, pp. 234-252.

Ahuja, J., Panda, T., Luthra, S., Kumar, A., Choudhary, S. and Garza-Reyes, J. (2019), "Do human critical success factors matter in adoption of sustainable manufacturing practices? An influential mapping analysis of multi-company perspective", Journal of Cleaner Production, Vol. 239, p. 117981.

Albukhitan, S. (2020), "Developing digital transformation strategy for manufacturing", Procedia

Significance of employee behaviours Computer Science, Vol. 170, pp. 664-671.

Alieva, J. and Haartman, R. (2020), "Digital Muda - the new form of waste by industry 4.0", Operations and Supply Chain Management: An International Journal, Vol. 13 No. 3, pp. 269-278.

Ammar, M., Haleem, A., Javaid, M., Walia, R. and Bahl, S. (2021), "Improving material quality management and manufacturing organizations system through industry 4.0 technologies", Materials Today: Proceedings, Vol. 45 No. 6, pp. 5089-5096.

Antonizzi, J. and Smuts, H. (2020), "The characteristics of digital entrepreneurship and digital transformation: a systematic literature review. Responsible design, implementation and use of information and communication technology", Proceedings of 19th IFIP WG 6.11 Conference on e-Business, e-Services, and e-Society, I3E 2020, Skukuza, South Africa, April 6-8, 2020, Part I, 12066, pp. 239-251.

Bai, C., Satir, A. and Sarkis, J. (2019), "Investing in lean manufacturing practices: an environmental and operational perspective", International Journal of Production Research, Vol. 57 No. 4, pp. 1037-1051.

Benešová, A. and Jiří Tupa, J. (2017), "Requirements for education and qualification of people in industry 4.0", Procedia Manufacturing, Vol. 11, pp. 2195-2202.

Bloomberg, J. (2018), "Digitization, digitalization, and digital transformation: confuse them at your peril", Forbes, 29 April 2018, available at: www.forbes.com/sites/jasonbloomberg/2018/04/29/ digitization-digitalization-and-digital-transformation-confuse-them-at-your-peril/?sh=69188fab2f2c (accessed 23 April 2021).

Buer, S., Semini, M., Strandhagen, J. and Sgarbossa, F. (2021), "The complementary effect of lean manufacturing and digitalisation on operational performance", International Journal of Production Research, Vol. 59 No. 7, pp. 1976-1992.

Bugdol, M. (2020), "The problem of fear in TQM - causes, consequences and reduction methods - a literature review", The TQM Journal, Vol. 32 No. 6, pp. 1217-1239.

Chaka, C. (2020), "Skills, competencies and literacies attributed to 4IR/industry 4.0: scoping review", IFLA Journal, Vol. 46 No. 4, pp. 369-399.

Chan, A., Hooi, L. and Ngui, K. (2021), "Do digital literacies matter in employee engagement in digitalised workplace?”, Journal of Asia Business Studies, Vol. 15 No. 3, pp. 523-540.

Chen, C., Lin, Y., Chen, W., Chao, C. and Pandia, H. (2021), "Role of government to enhance digital transformation in small service business", Sustainability, Vol. 13 No. 3, p. 1028.

Choi, D., Sung, C. and Park, J. (2020), "How does technology startups increase innovative performance? The study of technology startups on innovation focusing on employment change in Korea", Sustainability, Vol. 12 No. 2.

Ciano, M.P., Dallasega, P., Orzes, G. and Rossi, T. (2020), "One-to-one relationships between industry 4.0 technologies and lean production techniques: a multiple case study", International Journal of Production Research, Vol. 59 No. 5, pp. 1386-1410.

Coetzee, R., van Dyk, L. and van der Merwe, K. (2019), "Towards addressing respect for people during lean implementation", International Journal of Lean Six Sigma, Vol. 10 No. 3, pp. 830-854.

Demeter, K., Losonci, D. and Nagy, J. (2021), "Road to digital manufacturing - a longitudinal case-based analysis", Journal of Manufacturing Technology Management, Vol. 32 No. 3, pp. 820-839. 
IJLSS

14,1

Din, G., Shahani, N. and Baloch, M. (2021), "Impact of rewards system in employee's motivation in the organizational context: a quantitative study of manufacturing industry in UAE", Liberal Arts and Social Sciences International Journal (LASSIJ), Vol. 5 No. 1, pp. 105-122.

Durairatnam, S., Chong, S. and Jusoh, M. (2019), "People-related TQM practices, organisational culture, organisational justice and employee work-related attitudes for quality performance: a research agenda”, Global Journal of Management and Business Research, Vol. 19 No. 4, pp. 1-10.

Duriau, V.J., Reger, R.K. and Pfarrer, M.D. (2007), "A content analysis of the content analysis literature in organization studies: research themes, data sources, and methodological refinements", Organizational Research Methods, Vol. 10 No. 1, pp. 5-34.

Dutta, G., Kumar, R., Sindhwani, R. and Singh, R.K. (2020), "Digital transformation priorities of India's discrete manufacturing SMEs - a conceptual study in perspective of industry 4.0", Competitiveness Review: An International Business Journal, Vol. 30 No. 3, pp. 289-314.

Ejsmont, K. and Gladysz, B. (2020), "Lean industry 4.0 - wastes versus technology framework", in Panuwatwanich, K. and Ko, C.H. (Eds), The 10th International Conference on Engineering, Project, and Production Management, Lecture Notes in Mechanical Engineering, Springer, pp. 537-546.

Elo, S. and Kyngas, H. (2008), “The qualitative content analysis process”, Journal of Advanced Nursing, Vol. 62 No. 1, pp. 107-115.

Freddi, D. (2018), "Digitalisation and employment in manufacturing", AI and Society, Vol. 33 No. 3, pp. 393-403.

Gaffley, G. and Pelser, T. (2021), "Developing a digital transformation model to enhance the strategy development process for leadership in the South African manufacturing sector", South African Journal of Business Management, Vol. 52 No. 1, p. 12.

Gaiardelli, P., Resta, B. and Dotti, S. (2019)," "Exploring the role of human factors in lean management", International Journal of Lean Six Sigma, Vol. 10 No. 1, pp. 339-366.

García-Alcaraz, J., Flor-Montalvo, F., Avelar-Sosa, L., Sánchez-Ramírez, C. and Jiménez-Macías, E. (2019a), "Human resource abilities and skills in TQM for sustainable enterprises", Sustainability, Vol. 11 No. 22, p. 6488.

García-Alcaraz, J., Realyvasquez-Vargas, A., García-Alcaraz, P., Pérez de la Parte, M., Blanco Fernández, J. and Jiménez Macias, E. (2019b), "Effects of human factors and lean techniques on just in time benefits", Sustainability, Vol. 11 No. 7, p. 1864.

Georgiev, S. and Ohtaki, S. (2019), "Critical success factors for TQM implementation among manufacturing SMEs: evidence from Japan”, Benchmarking: An International Journal, Vol. 27 No. 2, pp. 473-498.

Ghobakhloo, M. (2020), "Determinants of information and digital technology implementation for smart manufacturing", International Journal of Production Research, Vol. 58 No. 8, pp. 2384-2405.

Ghobakhloo, M. and Ching, N. (2019), "Adoption of digital technologies of smart manufacturing in SMEs", Journal of Industrial Information Integration, Vol. 16, pp. 1-14.

Gillani, F., Chatha, K., Jajja, M. and Farooq, S. (2020), "Implementation of digital manufacturing technologies: antecedents and consequences", International Journal of Production Economics, Vol. 229, p. 107748.

Grandinetti, R., Ciasullo, M.V., Paiola, M. and Schiavone, F. (2020), "Fourth industrial revolution, digital servitization and relationship quality in Italian B2B manufacturing firms. An exploratory study", The TQM Journal, Vol. 32 No. 4, pp. 647-671.

Haipeter, T. (2020), "Digitalisation, unions and participation: the German case of "industry 4.0", Industrial Relations Journal, Vol. 51 No. 3, pp. 242-260.

Halim, F., Azman, A. and Malim, M. (2019), "Prioritising critical success factors of TQM in Malaysia aerospace industry using fuzzy AHP", Journal of Physics Conference Series, No. 1366, IOP Publishing. 
Hee, O. and Jing, K. (2018), “The influence of human resource management practices on employee performance in the manufacturing sector in Malaysia", International Journal of Human Resource Studies, Vol. 8 No. 2, pp. 129-147.

Henao, R., Sarache, W. and Gómez, I. (2019), "Lean manufacturing and sustainable performance: trends and future challenges", Journal of Cleaner Production, Vol. 208, pp. 99-116.

Iqbal, T., Jajja, M., Bhutta, M. and Qureshi, S. (2020), "Lean and agile manufacturing: complementary or competing capabilities?", Journal of Manufacturing Technology Management, Vol. 31 No. 4, pp. 749-774.

Jones, M., Hutcheson, S. and Camba, J. (2021), "Past, present, and future barriers to digital transformation in manufacturing: a review", Journal of Manufacturing Systems, Vol. 60, pp. 936-948.

Kassem, B. and Staudacher, A.P. (2021), "Implementation of digital tools for lean manufacturing: an empirical analysis", in Dolgui, A., Bernard, A., Lemoine, D., von Cieminski, G. and Romero, D. (Eds), Advances in Production Management Systems. Artificial Intelligence for Sustainable and Resilient Production Systems. APMS 2021. IFIP Advances in Information and Communication Technology, Vol. 633, Springer, Cham.

Kim, E. and Park, S. (2021), "Employees' perceptions of organizational learning: the role of knowledge and trust", Kybernetes, Vol. 50 No. 5, pp. 1521-1538.

Kipper, L., Iepsen, S., Dal Forno, A.J., Frozza, R., Furstenau, L., Agnes, J. and Cossul, D. (2021), "Scientific mapping to identify competencies required by industry 4.0", Technology in Society, Vol. 64, p. 101454.

Legner, C., Eymann, T., Hess, T., Matt, C., Bohmann, T., Drews, P., Madche, A., Urbach, N. and Ahlemann, F. (2017), "Digitalization: opportunity and challenge for the business and information systems engineering community", Business and Information Systems Engineering, Vol. 59 No. 4, pp. 301-308.

Lei, H., Leaungkhamma, L. and Le, P.B. (2020), "How transformational leadership facilitates innovation capability: the mediating role of employees' psychological capital”, Leadership and Organization Development Journal, Vol. 41 No. 4, pp. 481-499.

Leksic, I., Stefanic, N. and Veza, I. (2020), “The impact of using different lean manufacturing tools on waste reduction", Advances in Production Engineering and Management, Vol. 15 No. 1, pp. 81-92.

Liker, J.K. (2004), The Heart of the Toyota Production System: Eliminating Waste, in the Toyota Way: 14 Management Principles from the World's Greatest Manufacturer, McGraw-Hill, New York.

Lin, T., Sheng, M. and Wang, K. (2020), "Dynamic capabilities for smart manufacturing transformation by manufacturing enterprises", Asian Journal of Technology Innovation, Vol. 28 No. 3, pp. 403-426.

Llopis-Albert, C., Rubio, F. and Valero, F. (2021), "Impact of digital transformation on the automotive industry", Technological Forecasting and Social Change, Vol. 162, p. 120343.

Logesh, B. and Balaji, M. (2020), "Experimental investigations to deploy green manufacturing through reduction of waste using lean tools in electrical components manufacturing company", International Journal of Precision Engineering and Manufacturing-Green Technology, Vol. 8 No. 2, pp. 365-374.

Maisiri, W. and Van Dyk, L. (2021), "Industry 4.0 skills: a perspective of the South African manufacturing industry", SA Journal of Human Resource Management/SA Tydskrif Vir Menslikehulpbronbestuur, Vol. 19, p. a1416.

Martens, R. (2020), “Leadership to lean”, IEEE Transactions on Engineering Management, pp. 1-11.

Martínez-Caro, E., Cegarra-Navarro, J. and Alfonso-Ruiz, F. (2020), "Digital technologies and firm performance: the role of digital organisational culture", Technological Forecasting and Social Change, Vol. 154, p. 119962. 
IJLSS

14,1

Minh, K.S., Zailani, S., Iranmanesh, M. and Heidari, S. (2019), "Do lean manufacturing practices have negative impact on job satisfaction?", International Journal of Lean Six Sigma, Vol. 10 No. 1, pp. 257-274.

Mittal, S., Khan, M., Purohit, J., Menon, K., Romero, D. and Wuest, T. (2020), “A smart manufacturing adoption framework for SMEs", International Journal of Production Research, Vol. 58 No. 5 , pp. 1555-1573.

Moeuf, A., Lamouri, S., Pellerin, R., Tamayo-Giraldo, S., Tobon-Valencia, E. and Eburdy, R. (2020), "Identification of critical success factors, risks and opportunities of industry 4.0 in SMEs", International Journal of Production Research, Vol. 58 No. 5, pp. 1384-1400.

Mokudai, T., Schröder, M., Müller, M., Schaede, C., Holst, H., Sinopoli, R., Jürgens, U., Herrigel, G. and Aoki, K. (2021), "Digital technologies as lean augmentation: a preliminary study of Japanese automotive manufacturers", International Journal of Automotive Technology and Management, Vol. 21 No. 3, pp. 228-249.

Morton, S., Michaelides, R., Roca, T. and Wagner, H. (2019), "Increasing employee engagement in organizational citizenship behaviors within continuous improvement programs in manufacturing: the HR link", IEEE Transactions on Engineering Management, Vol. 66 No. 4, pp. 650-662.

Mugge, P., Abbu, H., Michaelis, T., Kwiatkowski, A. and Gudergan, G. (2020), "Patterns of digitization”, Research-Technology Management, Vol. 63 No. 2, pp. 27-35.

Mura, A. (2020), "What is digital adoption and how does it impact transformation?", User Lane, available at: www.userlane.com/what-is-digital-adoption-definition/\#: :text=Digital\% 20adoption $\% 20$ is $\% 20$ a $\% 20$ change,drive $\% 20$ innovation $\% 20$ and $\% 20$ optimize $\% 20$ processes (accessed 12 April 2021).

Nagaraj, T., Jeyapaul, R., Vimal, K. and Mathiyazhagan, K. (2019), "Integration of human factors and ergonomics into lean implementation: ergonomic-value stream map approach in the textile industry", Production Planning and Control, Vol. 30 No. 15, pp. 1265-1282.

O'Donnell, J. (2017), "IDC says get on board with the DX economy or be left behind", Tech Target, available at: https://searcherp.techtarget.com/news/450414723/IDC-says-get-on-board-with-theDX-economy-or-be-left-behind (accessed 23 April 2021).

Ogbeibu, S., Pereira, V., Emelifeonwu, J. and Gaskin, J. (2021), "Bolstering creativity willingness through digital task interdependence, disruptive and smart HRM technologies", Journal of Business Research, Vol. 124, pp. 422-436.

Okano, M., Santos, H., Ursini, E., Honorato, W. and Ribeiro, R. (2021), "Digital transformation as an agent of change in a pharmaceutical industry from the perspective of dynamic capabilities", 2021 IEEE 11th Annual Computing and Communication Workshop and Conference (CCWC), pp. 896-902.

Parschau, C. and Hauge, J. (2020), "Is automation stealing manufacturing jobs? Evidence from South Africa's apparel industry”, Geoforum, Vol. 115, pp. 120-131.

Permana, I., Afkar, E. and Augusta, H. (2021), "Differential diagnosis of digital culture in startup vs. non-startup companies in Indonesia to drive employee engagement and digital maturity", Journal of Humanities and Social Studies (JHSS), Vol. 5 No. 2, pp. 133-141.

Pham, T., Pham, C. and Pham, L. (2016), “Top management support, organizational learning, innovative behavior, employee commitment and organizational performance of manufacturing companies in Hai Phong", International Journal of Financial Research, Vol. 7 No. 3, pp. 54-64.

Popkova, E.G. and Sergi, B.S. (2020), "Human capital and AI in industry 4.0. Convergence and divergence in social entrepreneurship in Russia”, Journal of Intellectual Capital, Vol. 21 No. 4, pp. 565-581.

Porfírio, J., Carrilho, T., Felício, J. and Jardim, J. (2021), "Leadership characteristics and digital transformation”, Journal of Business Research, Vol. 124, pp. 610-619. 
Powell, D., Romero, D., Gaiardelli, P., Cimini, C. and Cavalieri, S. (2018), "Towards digital lean cyberphysical production systems: industry 4.0 technologies as enablers of leaner production", in Moon, I., Lee, G., Park, J., Kiritsis, D. and von Cieminski, G. (Eds) Advances in Production Management Systems. Smart Manufacturing for Industry 4.0, APMS 2018, IFIP Advances in Information and Communication Technology, Vol. 536, Springer.

Purba, C. (2021), "Digital transformation in the Indonesia manufacturing industry: the effect of elearning, e-task and leadership style on employee engagement", International Journal of Data and Network Science, Vol. 5 No. 3, pp. 361-368.

Purushothaman, M., Seadon, J. and Moore, D. (2020), "Waste reduction using lean tools in a multicultural environment”, Journal of Cleaner Production, Vol. 265, p. 121681.

Qiu, Y., Lou, M., Zhang, L. and Wang, Y. (2020), "Organizational citizenship behavior motives and thriving at work: the mediating role of citizenship fatigue", Sustainability, Vol. 12 No. 6, p. 2231.

Raj, A., Dwivedi, G., Sharma, A., Jabbour, A. and Rajak, S. (2020), "Barriers to the adoption of industry 4.0 technologies in the manufacturing sector: an inter-country comparative perspective", International Journal of Production Economics, Vol. 224, p. 107546.

Rauch, E., Linder, C. and Dallasega, P. (2020), "Anthropocentric perspective of production before and within industry 4.0", Computers and Industrial Engineering, Vol. 139, p. 105644.

Raweewan, M. and Kojima, F. (2020), "Digital lean manufacturing - collaborative university-industry education in systems design for lean transformation", Procedia Manufacturing, Vol. 45, pp. 183-188.

Reis, J., Amorim, M., Melão, N., Cohen, Y. and Rodrigues, M. (2020), "Digitalization: a literature review and research agenda", in Anisic, Z., Lalic, B. and Gracanin, D. (Eds), Proceedings on 25th International Joint Conference on Industrial Engineering and Operations Management IJCIEOM. IJCIEOM 2019, Lecture Notes on Multidisciplinary Industrial Engineering. Springer, Cham.

Richert, A., Shehadeh, M., Plumanns, L., Groß, K., Schuster, K. and Jeschke, S. (2016), "Educating engineers for industry 4.0: virtual worlds and human-robot-teams: empirical studies towards a new educational age", IEEE Global Engineering Education Conference (EDUCON), pp. 142-149.

Romero, D., Flores, M., Herrera, M. and Resendez, H. (2019a), "Five management pillars for digital transformation integrating the lean thinking philosophy", IEEE International Conference on Engineering, Technology and Innovation (ICE/ITMC), pp. 1-8.

Romero, D., Gaiardelli, P., Powell, D., Wuest, T. and Thürer, M. (2019b), "Rethinking Jidoka systems under automation and learning perspectives in the digital lean manufacturing world", IFACPapersOnLine, Vol. 52 No. 13, pp. 899-903.

Romero, D., Gaiardelli, P., Powell, D., Wuest, T. and Thürer, M. (2019c), “Total quality management and quality circles in the digital lean manufacturing world", APMS Conference Proceedings: Towards Smart Production Management Systems, Springer.

Romero, D., Gaiardelli, P., Thürer, M., Powell, D. and Wuest, T. (2019d), "Cyber-Physical waste identification and elimination strategies in the digital lean manufacturing world", in Ameri, F., Stecke, K., von Cieminski, G. and Kiritsis, D. (Eds), Advances in Production Management Systems. Production Management for the Factory of the Future. APMS 2019. IFIP Advances in Information and Communication Technology, Vol. 566, Springer, Cham.

Romero, D., Gaiardelli, P., Wuest, T., Powell, D. and Thürer, M. (2020), "New forms of Gemba walks and their digital tools in the digital lean manufacturing world", in Lalic, B., Majstorovic, V., Marjanovic, U., von Cieminski, G. and Romero, D. (Eds) Advances in Production Management Systems. Towards Smart and Digital Manufacturing, APMS 2020, IFIP Advances in Information and Communication Technology, Vol. 592, Springer.

Rossini, M., Cifone, F.D., Kassem, B., Costa, F. and Portioli-Staudacher, A. (2021), "Being lean: how to shape digital transformation in the manufacturing sector", Journal of Manufacturing Technology Management, Vol. 32 No. 9, pp. 239-259. 
Rowley, J. (2002), “Using case studies in research”, Management Research News, Vol. 25 No. 1, pp. 16-27.

Sancha, C., Wiengarten, F., Longoni, A. and Pagell, M. (2019), "The moderating role of temporary work on the performance of lean manufacturing systems", International Journal of Production Research, Vol. 58 No. 14, pp. 4285-4305.

Santhanam, N. and Srinivas, S. (2019), "Modeling the impact of employee engagement and happiness on burnout and turnover intention among blue-collar workers at a manufacturing company", Benchmarking: An International Journal, Vol. 27 No. 2, pp. 499-516.

Saraiha, U., Mariadassb, R., Abashahc, A. and Mutalib, S. (2021), "Employee performance in the perspectives of training, reward and motivation: evidences from the Malaysian manufacturing company", AIP Conference Proceedings, Vol. 2339, p. 020054.

Saxena, M. and Rao, S. (2019), “TQM, six sigma and lean”, International Journal of Applied Engineering Research, Vol. 14 No. 15, pp. 3442-3447.

Schumacher, S., Bildstein, A. and Bauernhansl, T. (2020), "The impact of the digital transformation on lean production systems", Procedia CIRP, Vol. 93, pp. 783-788.

Shahi, C. and Sinha, M. (2021), "Digital transformation: challenges faced by organizations and their potential solutions", International Journal of Innovation Science, Vol. 13 No. 1, pp. 17-33.

Shamim, S., Cang, S., Yu, H. and Li, Y. (2016), "Management approaches for industry 4.0: a human resource management perspective", 2016 IEEE Congress on Evolutionary Computation (CEC), Vancouver, BC, Canada, pp. 5309-5316.

Siedler, C., Dupont, S., Zavareh, M., Zeihsel, F., Ehemann, T., Sinnwell, C., Göbel, J., Zink, K. and Aurich, J. (2021), "Maturity model for determining digitalization levels within different product lifecycle phases", Production Engineering, Vol. 15 Nos 3/4, pp. 431-450.

Singh, J.P., Chand, P.K., Mittal, A. and Aggarwal, A. (2020), "High-performance work system and organizational citizenship behaviour at the shop floor", Benchmarking: An International Journal, Vol. 27 No. 4, pp. 1369-1398.

Slack, N., Chambers, S. and Johnston, R. (2010), "Operations management, 5th edition”, Pearson Education, Harlow, UK.

Sodhi, H.S., Singh, D. and Singh, B.J. (2020), "A conceptual examination of lean, six sigma and lean six sigma models for managing waste in manufacturing SMEs", World Journal of Science, Technology and Sustainable Development, Vol. 17 No. 1, pp. 20-32.

Soukupova, N., Adamová, M. and Krninská, R. (2020), "Industry 4.0: an employee perception (case of the Czech Republic)", Acta Universitatis Agriculturae et Silviculturae Mendelianae Brunensis, Vol. 68 No. 3, pp. 637-644.

Stöhr, M., Schneider, M. and Henkel, C. (2018), “Adaptive work instructions for people with disabilities in the context of human robot collaboration", IEEE 16th International Conference on Industrial Informatics (INDIN), pp. 301-308.

Sun, Y., Li, L., Shi, H. and Chong, D. (2020), “The transformation and upgrade of china's manufacturing industry in industry 4.0 era", Systems Research and Behavioral Science, Vol. 37 No. 4, pp. 734-740.

Talapatra, S., Uddin, M., Antony, J., Gupta, S. and Cudney, E. (2019), “An empirical study to investigate the effects of critical factors on TQM implementation in the garment industry in Bangladesh", International Journal of Quality and Reliability Management, Vol. 37 Nos 9/10, pp. 1209-1232.

Teryima, S.J., Timothy, A.T., Faajir, A., John, E. and Vivien, U. (2016), "Motivational factors as determinants of employee commitment and performance enhancement in profit-oriented firms: a survey of selected brewery manufacturing companies in Nigeria”, International Journal of Business and Economic Development, Vol. 4 No. 2, pp. 112-129.

Toledo, J.C., Gonzalez, R.V.D., Lizarelli, F.L. and Pelegrino, R.A. (2019), "Lean production system development through leadership practices”, Management Decision, Vol. 57 No. 5, pp. 1184-1203. 
Tortorella, G., Miorando, R., Caiado, R., Nascimento, D. and Staudacher, A. (2021), "The mediating effect of employees' involvement on the relationship between industry 4.0 and operational performance improvement", Total Quality Management and Business Excellence, Vol. 32 Nos 1/2, pp. 119-133.

Truant, E., Broccardo, L. and Dana, L. (2021), "Digitalisation boosts company performance: an overview of Italian listed companies", Technological Forecasting and Social Change, Vol. 173, p. 121173.

Van, H. and Nafukho, F. (2019), "Employee engagement antecedents and consequences in Vietnamese businesses", European Journal of Training and Development, Vol. 44 Nos 2/3, pp. 89-103.

Vereycken, Y., Ramioul, M., Desiere, S. and Bal, M. (2021), "Human resource practices accompanying industry 4.0 in European manufacturing industry", Journal of Manufacturing Technology Management, Vol. 32 No. 5, pp. 1016-1036.

Volberda, H., Khanagha, S., Baden-Fuller, C., Mihalache, O. and Birkinshaw, J. (2021), "Strategizing in a digital world: overcoming cognitive barriers, reconfiguring routines and introducing new organizational forms", Long Range Planning, Vol. 54 No. 5.

Voss, C., Johnson, M. and Godsell, J. (2016), “Case research”, in Karlsson, C. (Ed.) Research Methods for Operations Management, 2nd ed., Routledge, London, pp. 165-193.

Voss, C., Tsikriktsis, N. and Frohlich, M. (2002), "Case research in operations management", International Journal of Operations and Production Management, Vol. 22 No. 2, pp. 195-219.

Vukadinovic, S., Macuzic, I., Djapan, M. and Milosevic, M. (2019), "Early management of human factors in lean industrial systems", Safety Science, Vol. 119, pp. 392-398.

Wang, Y. and Han, M. (2020), "Research on the impact mechanism of organizational-based psychological ownership on the intelligent transformation of manufacturing enterprises: based on the perspective of technological change", Psychology Research and Behavior Management, Vol. 13, pp. 775-786.

Womack, J.P., Jones, D.T. and Roos, D. (1990), "The rise of lean production", The Machine That Changed the World, Macmillan, New York.

Wrede, M., Velamuri, V.K. and Dauth, T. (2020), "Top managers in the digital age: exploring the role and practices of top managers in firms' digital transformation", Managerial and Decision Economics, Vol. 41 No. 8, pp. 1549-1567.

$\mathrm{Xu}, \mathrm{Z}$., Chin, T. and Cao, L. (2020), "Crafting jobs for sustaining careers during china's manufacturing digitalization”, Sustainability, Vol. 12 No. 5, p. 2041.

Yan, J., Zhang, K., Zhu, W. and Fan, Y. (2019), "An empirical framework for soft CSFs of TQM in Chinese manufacturing companies", The TQM Journal, Vol. 31 No. 3, pp. 377-399.

Yin, R.K. (2014), Case Study Research: Design and Methods, Sage Publications, Thousand Oaks.

Zainuddin, A., Kuzaiman, N., Salleh, N., Kasolang, S. and Hoffmann, J. (2019), "Quality green lean energy leadership management practices in Malaysian automotive companies", Journal of Mechanical Engineering, Vol.16 No. 1, pp. 149-158.

Zangiacomi, A., Pessot, E., Fornasiero, R., Bertetti, M. and Sacco, M. (2020), "Moving towards digitalization: a multiple case study in manufacturing", Production Planning and Control, Vol. 31 Nos 2/3, pp. 143-157.

Zhou, W. and Velamuri, V. (2018), "Key contextual success factors for employee innovative behavior: a study in a foreign manufacturing subsidiary in China", Cogent Business and Management, Vol. 5 No. 1, p. 1471770.

\section{Corresponding author}

Jamila Alieva can be contacted at: jamila.alieva@hig.se 


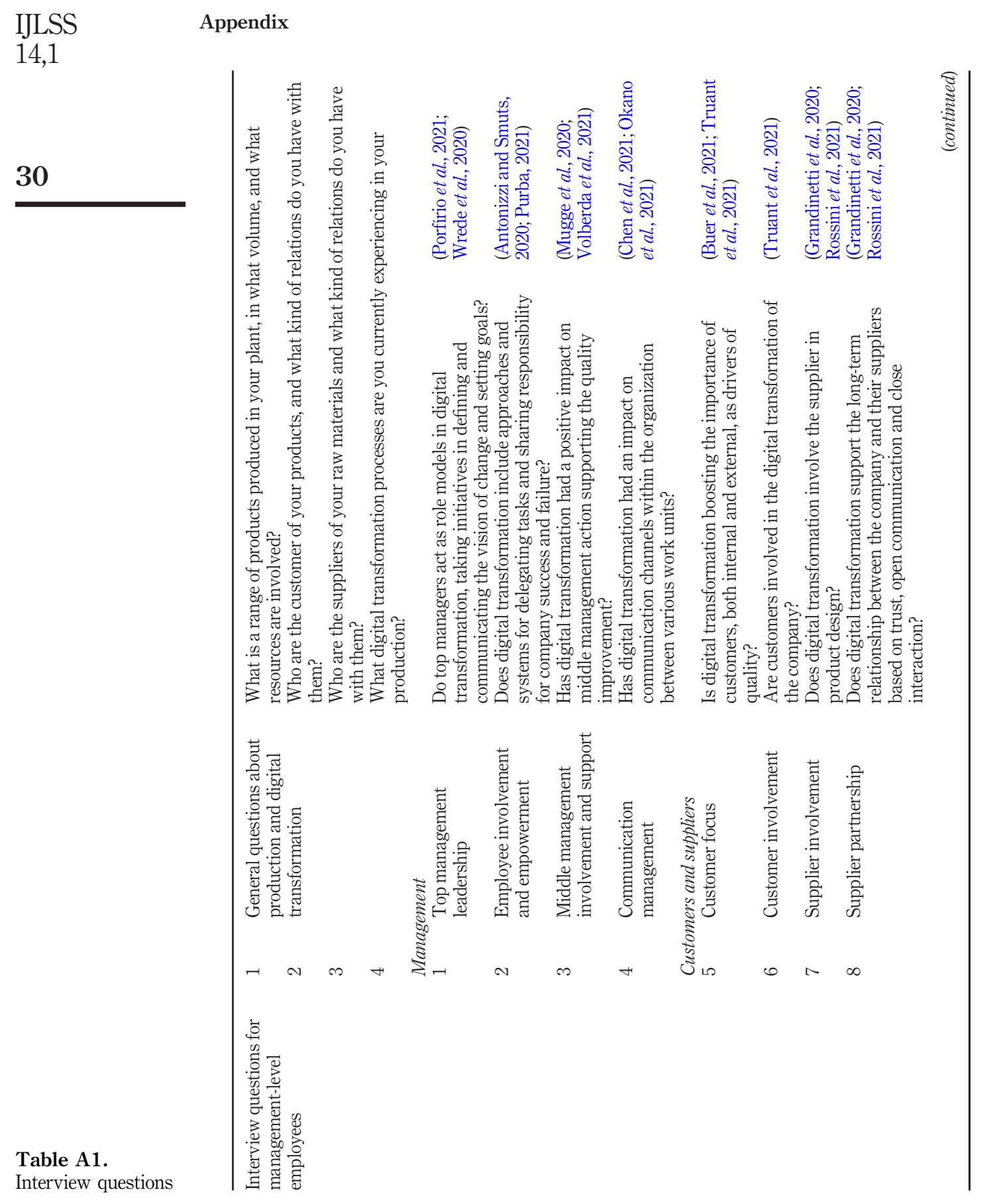


Significance of employee

behaviours

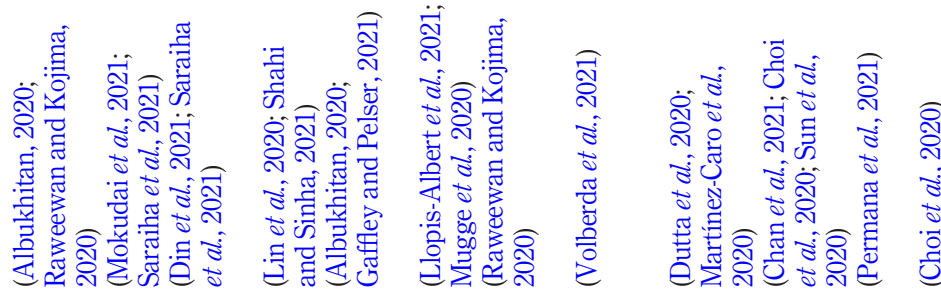

胥

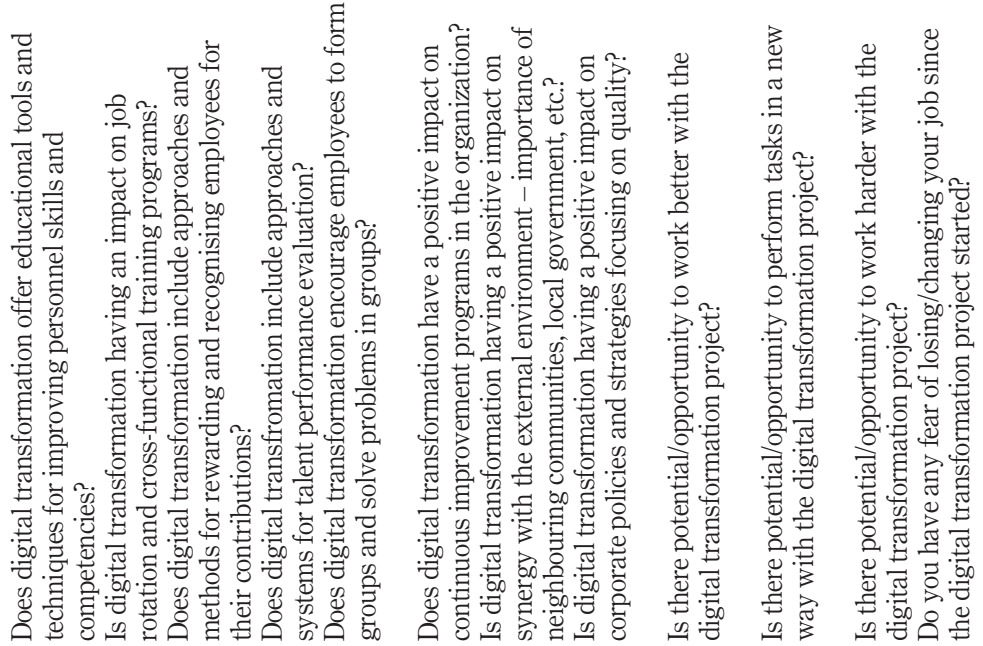

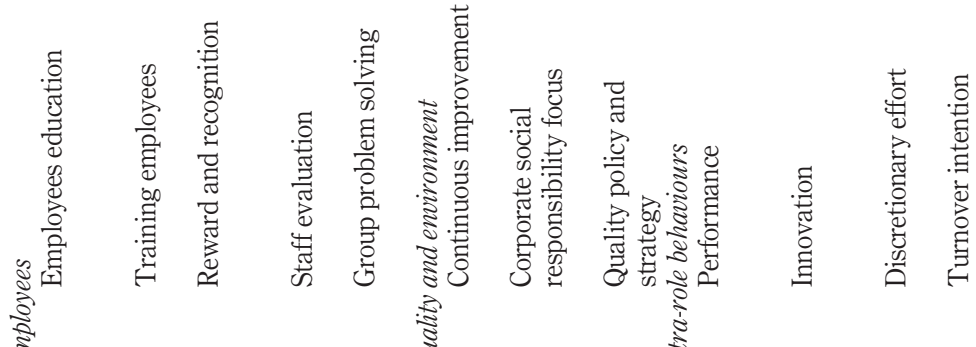

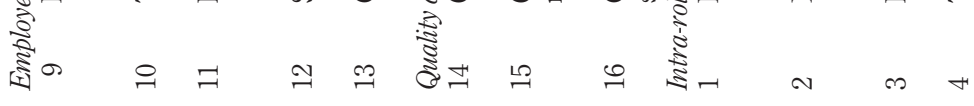

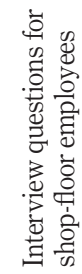

Table A1. 


\section{IJLSS}

14,1

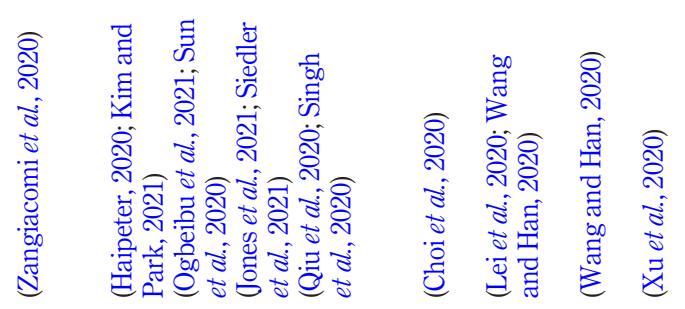

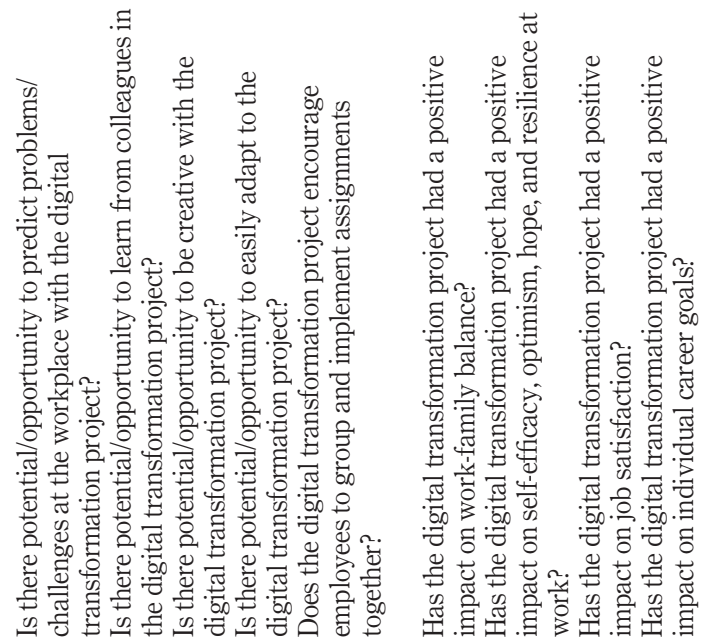

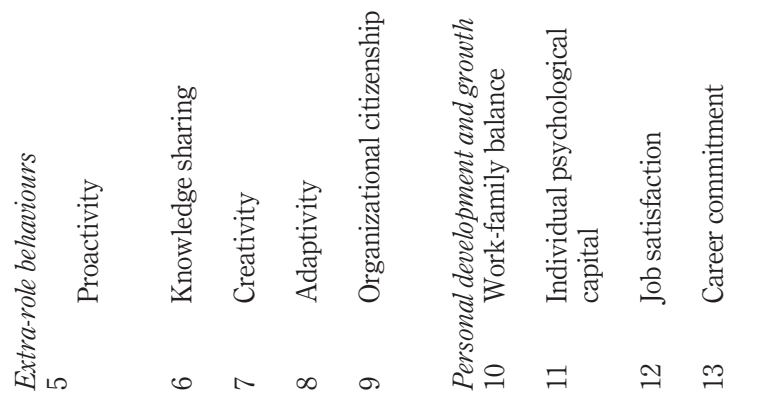

Table A1. 